\title{
Information Preference and Information Supply Efficiency Evaluation before, during, and after an Earthquake: Evidence from Songyuan, China
}

\author{
Shasha Li ${ }^{1}$, Xinyu Peng ${ }^{1}$, Ruiqiu Pang ${ }^{1, *}, \mathrm{Li} \mathrm{Li}^{1}{ }^{1}$ Zixuan Song ${ }^{2}$ and Hongying $\mathrm{Ye}^{3}$ \\ 1 Jangho Architecture College, Northeastern University, Shenyang 110169, China; \\ lishasha@mail.neu.edu.cn (S.L.); 20175857@stu.neu.edu.cn (X.P.); lili1118@mail.neu.edu.cn (L.L.) \\ 2 Rosedale Academy Shenyang Campus, Shenyang 110011, China; songzixuan0730@163.com \\ 3 China Building Technique Group Co., Ltd., Beijing 100013, China; yhycmc@126.com \\ * Correspondence: pangruiqiu@mail.neu.edu.cn
}

check for

updates

Citation: Li, S.; Peng, X.; Pang, R.; Li, L.; Song, Z.; Ye, H. Information Preference and Information Supply Efficiency Evaluation before, during, and after an Earthquake: Evidence from Songyuan, China. Int. J. Environ. Res. Public Health 2021, 18, 13070. https://doi.org/10.3390/ijerph182413070

Academic Editors: Liliana Cori, Fabrizio Bianchi and Ennio Cadum

Received: 8 October 2021

Accepted: 9 December 2021

Published: 11 December 2021

Publisher's Note: MDPI stays neutral with regard to jurisdictional claims in published maps and institutional affiliations.

Copyright: (c) 2021 by the authors. Licensee MDPI, Basel, Switzerland. This article is an open access article distributed under the terms and conditions of the Creative Commons Attribution (CC BY) license (https:// creativecommons.org/licenses/by/ $4.0 /)$.

\begin{abstract}
Efficient risk communication is aimed at improving the supply of risk information to meet the information needs of individuals, thus reducing their vulnerability when facing the risk of emergency. There is little information available in the literature regarding information preference from an individual's need perspective, and there is a lack of differentiation in evaluation between information need and supply. Under the guidance of the crisis stage analysis theory, using multiple response analysis and weighted analysis methods, this study explores earthquake disaster information content and communication channel preferences, and develops an information deviation index (IDI) to evaluate the efficiency of risk communication before, during, and after an earthquake. A questionnaire-based survey of 918 valid respondents in Songyuan, China, which had been hit by a small earthquake swarm, was conducted to provide practical evidence for this study. The results indicated the following. Firstly, the information needs of individuals are highly differentiated in the different stages of an earthquake. From pre-disaster to post-disaster, individuals show a shift in information need from "preparedness and response knowledge" to "disaster information", then to "disaster information and disaster relief information" in parallel, to "reconstruction and reflection information". Based on the above analysis, a composition of the main earthquake disaster information is proposed for different stages. Secondly, by measuring the values of the IDI, we found that most individuals' information needs were met for the earthquake. Thirdly, the TV and the internet were the two preferred commutation channels for acquiring disaster information from among all the effective channels in all the stages.
\end{abstract}

Keywords: earthquake disaster; information preference; information deviation index; crisis stage analysis theory; risk communication

\section{Introduction}

What is a disaster? "A serious disruption of the functioning of a community or a society at any scale due to hazardous events interacting with conditions of exposure, vulnerability and capacity, leading to one or more of the following: human, material, economic and environmental losses and impacts" [1]. Earthquakes are one of the most difficult hazards to be predicted and can result in massive casualties, property losses, and loss of municipal infrastructure. It is important for individuals to acquire sufficient earthquake disaster information so that, when faced with an earthquake, they are able to make the right decisions and take rapid actions with regard to mitigation measures and adjustments [2-13]. Research on the public's disaster information acquisition content and channel preferences may help to improve the efficiency of information supply. For example, if a communication channel is found to be effective in motivating the public to respond proactively to risk information, but is used sparingly, its effectiveness is limited [14,15]. 
Alternatively, if the public is eager to learn about some aspect of the risk, but the information is not available when it is released, the communication is also a failure. However, research on public disaster information preferences is often underappreciated [11-13].

Information plays an important role in disaster management and is an indispensable resource in disasters [15]. The theme of the World Disasters Report 2005 [16] is "Information in Disasters", and it systematically reviews the functions, sources, and channels of emergency information. Previous studies on earthquake disaster information mainly focused on two areas. The first area is research on earthquake disaster information classification. Information classification is distinguishing and classifying information in line with certain principles and methods according to the attributes or characteristics of the information content, establishing a certain classification system and arrangement order [17]. Chinese scholars have conducted many studies in the field of earthquake emergency information classification [18-24]. For instance, Nie et al. [18] proposed a classification system for basic earthquake emergency data. Su et al. [19] divided earthquake emergency information into seventeen categories. Bai et al. [20] classified earthquake emergency site information into four categories: earthquake information, disaster information, emergency response information, and disposal benefit information. Based on the historical earthquake disaster experience, emergency rescue experience and relevant national standards, on-site disaster information was divided into nine categories by Zhu et al. [21]. Dong et al. [22] categorized earthquake emergency disaster information into four categories, namely seismic information, earthquake zone background information, disaster information, and emergency response. Zhang et al. [23] ordered earthquake emergency disaster information into six categories. Su et al. [24] divided earthquake emergency information into eight categories. In addition, Sapountzaki [25] and Fokaefs [26] proposed that earthquake emergency information be grouped into four types of messages. See Table 1 for details.

Table 1. Earthquake emergency disaster information classification.

\begin{tabular}{|c|c|}
\hline Scholars & Earthquake Emergency Information Classification \\
\hline Nie et al. [18] & $\begin{array}{l}\text { Maps; socio-economic statistics; earthquake basic data; engineering earthquake data; disaster influence } \\
\text { background; disaster-related factors; disaster relief force reserve; earthquake emergency contact; earthquake } \\
\text { emergency plan. }\end{array}$ \\
\hline Su et al. [19] & $\begin{array}{l}\text { Group of the basic background; earthquake disasters and disaster relieving background; law and regulations; } \\
\text { the EER prearranged scheme and disaster reduction planning; existing earthquake disaster countermeasures; } \\
\text { experience from earthquake disaster reduction demonstrations and maneuvers; seismic station networks; } \\
\text { emergency communications; historical earthquakes; earthquake disaster relieve cases; disaster relieve capacity } \\
\text { reserve conditions; earthquake hazards; earthquake disasters; emergency decision-making and its assistant } \\
\text { knowledge; disaster field status; allotment and deployment information of the disaster relieve materials and } \\
\text { personnel; social response circumstances. }\end{array}$ \\
\hline Bai et al. [20] & $\begin{array}{l}\text { Essential earthquake information; damage information; emergency response information; disposal } \\
\text { efficiency information. }\end{array}$ \\
\hline Zhu et al. [21] & $\begin{array}{l}\text { Seismic conditions; casualties; housing damage; secondary disasters; damage to transportation systems; } \\
\text { damage to water supply systems; damage to power supply systems; damage to gas supply systems; damage } \\
\text { to communication systems. }\end{array}$ \\
\hline Dong et al. [22] & Seismic information; background information of earthquake zone; disaster information; emergency response. \\
\hline Zhang et al. [23] & $\begin{array}{l}\text { ion; disaster information; earthquake area background information; emergency response } \\
\text { information; popular science information. }\end{array}$ \\
\hline Su et al. [24] & $\begin{array}{l}\text { Location information; time information; disaster investigation; social public opinion; emergency rescue; } \\
\text { emergency support; non-emergency; comprehensive classes. }\end{array}$ \\
\hline $\begin{array}{l}\text { Sapountzaki [25] } \\
\text { Fokaefs [26] }\end{array}$ & Informative messages; warning messages; consulting messages; guiding messages \\
\hline
\end{tabular}

The classification of earthquake emergency disaster information provides an important reference for our research. However, to summarize the above literature, we found that:

(a) The earthquake disaster information mentioned above only referred to earthquake emergency information after earthquake disasters, and there was a lack of attention paid 
to information prior to the earthquake. Risk communication spans every phase of the (disaster) risk management cycle, not only the emergency [26];

(b) All the earthquake disaster information was collected and extracted from the internet, and such indirectly acquired information cannot reveal the information needs of general public in detail;

(c) It was unclear who the users of the earthquake disaster information were. The users may have come from the government category (i.e., government decision-making departments or decision makers), the industry category (i.e., industry information departments or industry information practitioners, or scientific research and engineering technicians), or the public category (i.e., social public groups or individuals, or mass media) [27]. There is a lack of clarification on the information audience.

The second area is research on the earthquake disaster information needs of a certain group. Jeffrey [28] explored the preferences of information needs in three phases: before, during, and after a crisis, while Rego [29] studied the information needs of disaster managers before and after disasters. Yang and Liu [30] investigated the basic orientation and characteristics of the information needs of the public in a crisis situation, taking the 12 May earthquake in 2008 as an example, and concluded that the public's information needs were differentiated at different stages of the earthquake. Sha and $\mathrm{Xu}$ [31] constructed an information analysis framework for emergency information needs based on the activity theory. Lei et al. [32] proposed a general and systematic framework for emergency information needs. Wang et al. [33] preliminarily summarized the information needs of earthquake emergency rescue, and put forward some suggestions on the information acquisition of major earthquakes and catastrophes. Zhou et al. [34], taking the Ms5.1 Sichuan Qingbaijiang earthquake as an example, studied the information product' needs of earthquake emergency personnel and scientific research personnel. Zhang et al. [35], taking the members of the earthquake relief headquarters at all levels in Yunnan as the research objects, analyzed their earthquake emergency information needs. Most of the above studies used direct investigation methods to obtain data and to accurately acquire earthquake disaster information needs for a specific population; however, an evaluation of the difference between information need and supply was lacking.

Numerous sources of information are involved in crisis communications, providing information to both at-risk and general audiences [36,37]. However, selecting the most effective channels can still be challenging. Traditional mass media mainly refers to television, radio and newspapers and magazines. Mass media has been found to be the most utilized channel of information dissemination during disasters [12,14,26,38-43]. Among them, radio is considered to be the most frequently used information dissemination channel in crisis events $[12,14,44-46]$. Furthermore, of course, there are studies which show that television remains the most common channel that audiences use in times of crisis [26,47-49]. Compared with traditional media, social media is also considered to be an important channel [50-56] for risk information due to its interactivity and speed. In addition to traditional media and new media, another information dissemination channel that cannot be ignored is interpersonal communication, which mainly refers to communication and dissemination among family members, friends, and neighbors. This informal information channel is considered to be one of the most important information sources during disasters $[14,57,58]$. Moreover, short message service (SMS) is applied widely by agencies worldwide [59], for instance, the US federal emergency management [60,61], Swiss National Weather Agency [62], and the Meteorological Service of New Zealand [61]. Most studies have focused on the information acquisition channels at one stage of a sudden crisis event [14], and discussion of the integrity of information disseminated channels has been missing.

To address these issues, this paper attempts to discuss the following issues:

(a) From the perspective of the needs of residents in earthquake-stricken areas, we attempt to explore their earthquake disaster information preferences, that is, what information content is needed and how this information should be disseminated. Finally, 
we propose the ideal composition of main disaster information at different stages of an earthquake;

(b) Risk communication efficiency based on whether the residents' information needs are being met. We develop an information deviation index (IDI) to evaluate the difference between the information needs and supply.

This study is presented in six sections. Following the introduction, Section 2 introduces the crisis stage analysis theory through a theoretical lens. Section 3 introduces the study area, the use of the questionnaire-based survey, the research indicators and the data analysis techniques employed. The research findings are highlighted and discussed in Sections 4 and 5. The Section 6 presents our conclusion, and discusses the limitations, future studies, and the implications of this study.

\section{Theoretical Lens}

The crisis stage analysis theory by Fink [63] is one of the most influential theories in the risk communication field. Fink (2002) proposed a four-stage pattern for crisis communication events. The four stages are crisis prodromal stage, crisis acute stage, crisis chronic stage, and crisis resolution stage. The fundamental purpose of this framework is, according to the basic characteristics of crisis events with stages, to study the characteristics of information communication in crisis events and to acquire coping strategies for crisis communication at different stages. As Fink (2002, p. 21) explained, "By dissecting a crisis and taking a closer, microscopic look at each phase, you may be better able to spot these stages in the future".

\subsection{Crisis Prodromal Stage}

The crisis prodromal stage is the easiest period in which to resolve crisis events, but it is easily ignored as obvious signs of the event have not yet occurred. In this period, in order to play a preventive and proactive role for the future, the most important work is to prepare for the crisis (which includes psychological and material preparation). Some scholars define the crisis prodromal stage as the period from the occurrence of a disaster to the beginning of the dissemination of disaster information [64].

In this study, the crisis prodromal stage is defined differently and has a longer time front, which refers to the time in daily life before an earthquake occurs; that is, the time before the earthquake disaster occurs in the area where residents live.

\subsection{Crisis Acute Stage}

The sudden outbreak of a crisis event, although short-lived, has a great social impact and causes loss of life and property, with information about the state of affairs spreading rapidly and immediately attracting widespread social attention. It can be said that the crisis outbreak period is the most difficult and urgent period in crisis management [65].

The emergent period in this study refers to the time immediately after the occurrence of an earthquake (i.e., the moment or day of the earthquake), in a state of emergency [66], which is the period from the beginning of the dissemination of earthquake disaster information to the rapid dissemination of earthquake disaster information [64].

\subsection{Crisis Chronic Stage}

When a crisis event enters the chronic stage from the acute stage, the damage caused has already been revealed and the large-scale organization of rescue work has begun. At this time, the public is in a negative mood, and the demand for information is at its maximum. This stage is the most active period for social opinion, so if information from formal channels is not released in a timely manner, all kinds of rumors and gossip may spread and cause group panic.

The chronic stage in this study refers to the earthquake relief period, which emphasizes the stage after the public learns the basic information about the earthquake, including both the post-earthquake emergency period and the relief period after the emergency 
period [66]. In other words, the stage when earthquake information spreads rapidly until it subsides [64].

\subsection{Crisis Resolution Stage}

In the crisis resolution stage, public attention shifts from the crisis itself to eliminating the effects of the event. In this stage, the crisis is fully controlled and people begin to return to the normal order of life and production, and to rebuild their homes according to the government's plan.

The crisis resolution stage in this paper refers to the post-disaster reconstruction period, including both the later period of earthquake relief and the reconstruction period after earthquake relief [66]. At this time, the disaster is properly resolved, people's lives return to normal, material production is restored, social panic is quelled, and the whole society returns to the state before the disaster.

The advantage of Fink's crisis stage analysis theory is that it provides a broader perspective to understanding the characteristics of the crisis, and it also provides a comprehensive and cyclical approach to the whole process of crisis management. The four stages of a crisis event are periodical processes that show different characteristics [65,67-69] (Table 2). Although the proposed stages lack detail and seem to be linearly deterministic, the framework still provides a complete examination of the crisis process, i.e., from its prodrome, development, and sudden change, to its resolution. This is of some relevance to the study of earthquake disaster. In this study, we suggest a timeline for the Songyuan earthquake according to Fink's crisis stage analysis theory. Further, we discuss the earthquake disaster information content and communication channel preferences, and evaluate the information supply efficiency for the periods when the public perceive different stages of the earthquake disaster.

Table 2. Periodicity and the characteristics of the stages of crisis events.

\begin{tabular}{lll}
\hline Stages & Characteristics & Actions \\
\hline \multirow{2}{*}{ Crisis Prodromal Stage } & $\begin{array}{l}\text { a. The result of contradiction accumulation; } \\
\text { b. Unnoticeable; } \\
\text { c. Easiest stage of crisis management. }\end{array}$ & $\begin{array}{l}\text { a. Crisis identification } \\
\text { b. Crisis prevention } \\
\text { c. Crisis preparation }\end{array}$ \\
\hline \multirow{2}{*}{ Crisis Acute Stage } & $\begin{array}{l}\text { a. The shortest duration but the longest feeling; } \\
\text { b. Greatest damage to society; } \\
\text { c. High social attention. }\end{array}$ & $\begin{array}{l}\text { a. Crisis early warming } \\
\text { b. Crisis response } \\
\text { c. Crisis emergency disposal }\end{array}$ \\
\hline \multirow{2}{*}{ Crisis Chronic Stage } & $\begin{array}{l}\text { a. Long duration; } \\
\text { b. Crisis management helps to shorten the duration; } \\
\text { c. Crisis losses have been caused. }\end{array}$ & $\begin{array}{l}\text { a. Crisis response } \\
\text { b. Emergency disposal } \\
\text { c. Emergency rescue }\end{array}$ \\
\hline \multirow{2}{*}{ Crisis Resolution Stage } & $\begin{array}{l}\text { a. Complete relief from crisis impact; } \\
\text { b. Social attention turns to eliminate event impact; } \\
\text { c. Linked to the next prodromal stage. }\end{array}$ & $\begin{array}{l}\text { a. Post-disaster treatment } \\
\text { b. Post-disaster recovery and reconstruction }\end{array}$ \\
\hline
\end{tabular}

\section{Materials and Methods}

\subsection{Study Area}

The area of interest in this study is Songyuan (Figure 1), a city in the midwest of Jilin province, China, located at $123^{\circ} 6^{\prime}-126^{\circ} 11^{\prime} \mathrm{E}$ and $43^{\circ} 59^{\prime}-45^{\circ} 32^{\prime} \mathrm{N}$. Songyuan is the only VIII degree high earthquake intensity zone in Jilin province, and is determined as one of the key monitoring defensive regions of China [70]. There are three tectonic lineaments in Songyuan: the northeast trending Fuyu-Zhaodong Fault; the north-west trending Second Songhua River Fault; and the north-north trending Nen River Fault [71]. Songyuan City includes Changling County; Qianguo County; Qian'an County; Fuyu County-level City; and Ningjiang District. 


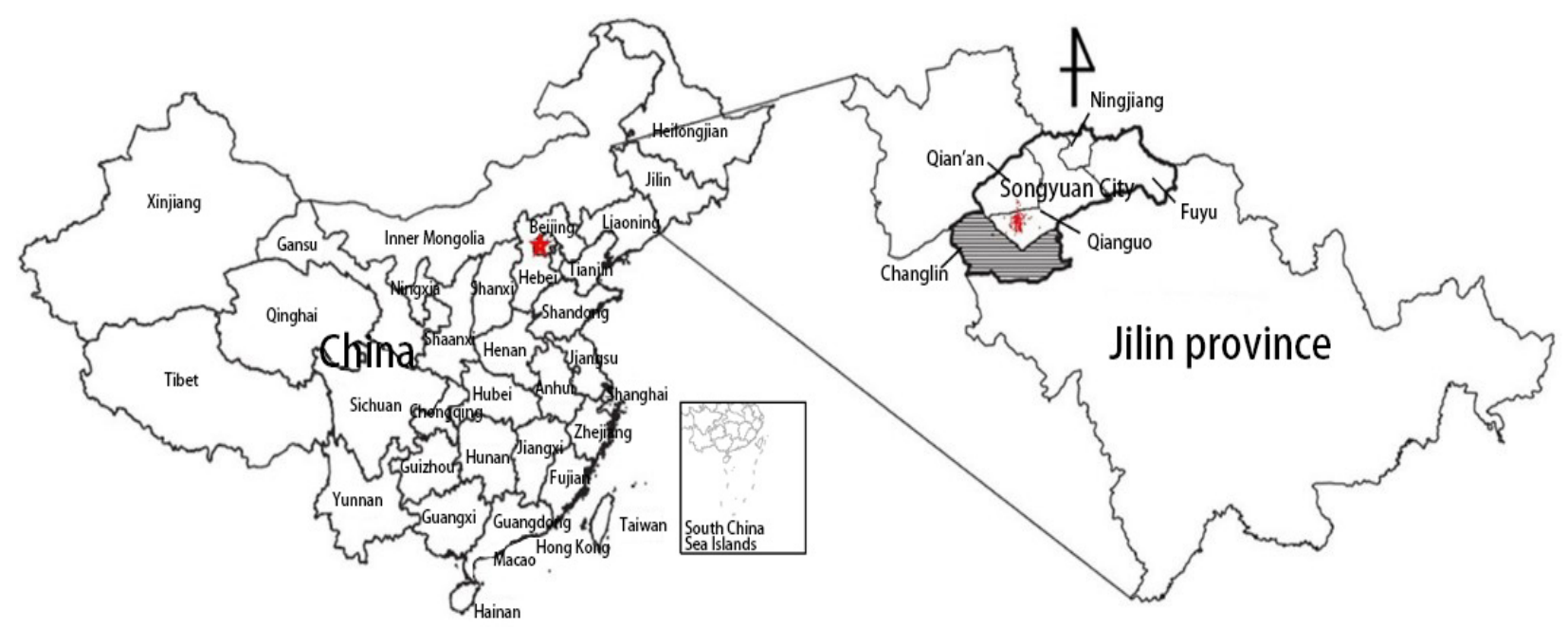

Figure 1. Location of study area. Note: The red spot in Jilin province indicates the epicenter of the earthquake swarm. The shaded part is the survey area.

In 1119 A.D., a destructive earthquake of magnitude $6 \frac{3}{4}$ occurred in Songyuan City, the largest shallow-focus earthquake recorded in Northeast China to date. According to the record in the book Big King Kingdom History, "thousands of people died in the earthquake" [72]. In 2003, a rare earthquake swarm occurred here for the first time since Jilin province was established. On 31 March, 2006, the city was hit by a second earthquake swarm, with the maximum magnitude reaching to 5.0. On 31 October, 2013, an Ms. 5.5 earthquake occurred again in this area, and more than 200 earthquakes occurred in the following month, including more than 10 earthquakes with Ms. $\geq 4.0$. In particular, Ms. 5.3, Ms. 5.8, and Ms. 5.0 earthquakes occurred in situ on 22 and 23 November, respectively $[73,74]$, as shown in Table 3. The Ms. 5.8 earthquake was the largest earthquake in the Songyuan area since 1119 A.D. The affected population in the Songyuan area reached more than 200,000, and severe damage was caused. Thirteen people were injured [75], and more than 57,000 houses were damaged in Qianguo County, Qian'an County, and Changling County, including 16,000 houses that were severely destroyed, 40,000 houses that were slightly damaged, and nearly 310 houses collapsed [76]. The economic loss is up to CNY 20 billion [76]. The worst-hit areas were Chaganhua Town in Qianguo County and Anzi Town in Qian'an County (the area around the epicenter, red zone in Figure 1). The earthquakes occurred in winter where the extreme minimum temperature was $-36.1{ }^{\circ} \mathrm{C}$ in the affected areas. As the damaged houses were unable to be repaired and rebuilt in the winter, the victims had to find accommodation with relatives and friends or rent houses in other areas to get through the winter, which meant that all the people in the two towns left the area. Therefore, this study chose Changling County as the survey area, given that it was the closest to the epicenter and therefore more representative.

\subsection{Data Collection}

\subsubsection{Questionnaire Design}

The anonymous questionnaire in Mandarin consisted of three sections. The first section asked questions on information seeking behavior and its possible determinants (seen [3] for details). The second section surveyed the earthquake disaster information needs (information expected acquisition), information supply (information actual acquisition), and the communication channels used during daily life, earthquake emergencies, earthquake relief, and post-disaster reconstruction, which were used in this research. This section was designed according to the recent literature on earthquake information classification [20-26] and the basic information needs of individuals in earthquake disasters [66], and was newly developed (Supplementary File S1 with * sign). As people in risky situations tend to acquire various types of information through multiple channels, this section of the 
questionnaire was in the form of multiple choice. As well, a survey on the reliability of information sources and information dissemination channels was conducted. All the items were measured by a five-point Likert-type scale ranging from $1-5$, with the higher scores indicating higher reliability with the statement. The third section collected the information on the socioeconomic and housing characteristics of the respondents, such as gender, age, education, income, housing ownership, housing type, and housing structures, etc., with two ways to fill in the blanks and choose the answers (seen Supplementary File S1).

Table 3. Basic seismic parameters of Songyuan Ms. $\geq 5.0$ earthquake swarm in 2013 [73,74].

\begin{tabular}{|c|c|c|c|c|c|}
\hline Serial Number & $\begin{array}{l}\text { Earthquake Time } \\
(\mathrm{GMT}+8)\end{array}$ & $\begin{array}{l}\text { Latitude } \\
\left({ }^{\circ}\right)\end{array}$ & $\begin{array}{c}\text { Longitude } \\
\left({ }^{\circ}\right)\end{array}$ & $\begin{array}{c}\text { Focal Depth } \\
(\mathbf{k m})\end{array}$ & Magnitude \\
\hline 1 & 31 October 2013 11:03 & 44.60 & 124.18 & 8 & 5.5 \\
\hline 2 & 31 October 2013 11:10 & 44.60 & 124.20 & 6 & 5.0 \\
\hline 3 & 22 November 2013 16:18 & 44.72 & 124.14 & 8 & 5.3 \\
\hline 4 & 23 November 2013 06:04 & 44.60 & 124.10 & 9 & 5.8 \\
\hline 5 & 23 November 2013 06:32 & 44.60 & 124.10 & 8 & 5.0 \\
\hline
\end{tabular}

\subsubsection{Implementation}

The data were collected in Changling County in Songyuan City, China in March 2014. Considering that the sample design of the survey needed cater to different regions as well as to residents with different demographic attributes and other factors, the survey therefore started at the schools with the guardians of the students as the research target using a multi-stage random sampling method to draw the sample. The specific sampling process was divided into three stages.

The first stage was the extraction of schools. In order to increase the representativeness of the schools as much as possible, using the simple random sampling method, six representative schools (No. 1 Primary School; No. 2 Primary School; No. 3 Primary School; No. 4 Primary School; No. 1 Junior High School; and No. 3 Senior High School) were selected to participate. The six schools were all part of the school district system, leading to a group distribution of the surveys, therefore achieving wide coverage.

The second stage was the sampling of classes. One class from each grade in each elementary school and five classes from each grade in each middle and high school were randomly selected in turn in each school, sampled on a non-release back sampling basis.

The third stage was the extraction of students. A total of 15 students were selected from the sampled elementary classes using systematic sampling (including 20 students in each of the first and second grades), and 20 students were selected from the middle and high school classes using systematic sampling, for a final total of 1000 students. With permission from the selected local schools, the school students received the questionnaires as a form of homework and delivered it to one of their guardians. A total of 1000 questionnaires were sent out, and 973 were completed with a response rate of $97.3 \%$. There were three possible reasons for this high response rate: one was the recent earthquake swarm experience, so the topic of this survey was related to the parents' own daily lives; the second reason is the respect paid by Chinese parents to teachers' authority (i.e., they usually follow teachers' requests) [77]; and the third was that the students believed they would be awarded a mark for filling in the questionnaire (homework).

\subsection{Research Indicator}

The information deviation index (IDI) refers to the proportion of the difference between the expected information to be acquired (information need) and the actual information acquired (information supply) with the expected information to be acquired:

$$
\text { Formula: } \mathrm{D}=(\mathrm{E}-\mathrm{A}) / \mathrm{E}
$$


where E represents the information expected to be acquired; A represents the information actually acquired; and $\mathrm{D}$ represents the information deviation index.

This means that, when the IDI value tends to 0 , the information expected to be acquired and the information actually acquired is symmetrical; when the IDI value is positive, the information expected to be acquired is greater than the information actually acquired (i.e., the public's information requirements fall short); and when the IDI value is negative, the information expected to be acquired is less than the information actually acquired (i.e., the public's information requirements have been achieved). The greater the value of the IDI, the greater the gap between the information expected to be acquired and the information actually acquired. Conversely, the smaller the IDI value, the closer the information actually acquired is to the information expected to be acquired.

\subsection{Analysis Techniques}

\subsubsection{Multiple Response Analysis}

Multiple response analysis, also known as polynomial analysis, has two methods: the first is the dichotomies method; and the second is category method [78]. This research adopted the dichotomies method; that is, each choice in the multiple-choice question was regarded as a variable in SPSS 16.0, and each variable was valued by 0 or 1 . A value of 1 means you chose this choice, and 0 means you did not choose it. Subsequently, multiple response sets were defined, the basic variables were coded as dichotomies variable sets, and then a frequency analysis was carried out on this basis.

In this research, multiple-response analysis was used to examine the frequency (percentage) statistics of the information expected to be acquired; the information actually acquired; and the communication channels used by the public in the earthquake zone during the prodromal, acute, chronic, and crisis resolution stages of the earthquake disaster.

\subsubsection{Weighted Analysis}

After acquiring the statistics of the frequency (percentages) of the information expected to be acquired and the information actually acquired by the public in the earthquake zone during the prodromal, acute, chronic, and crisis resolution stages of the earthquake disaster, a weighted analysis of each data was needed to facilitate the calculation of IDI in each stage.

\section{Results}

\subsection{Socioeconomic and Housing Characteristics of Respondents}

Among the 973 returned questionnaires, 918 questionnaires offered valid responses. Males were slightly over-represented (52.1\%). Approximately $90 \%$ of survey participants were between the ages of 31 and 50 . Approximately half of them had a high school degree or above, and over $90 \%$ of respondents earned less than CNY 100,000 per family per year. More than $80 \%$ owned their own house, with bungalows (43.9\%) and multilayer buildings $(47.7 \%)$ as the main housing styles, with masonry-concrete structures $(52.4 \%)$ and reinforced-concrete structures $(44 \%)$ as the main housing structures.

\subsection{Information Content Preferences of Earthquake Disaster}

4.2.1. The Prodromal Stage of an Earthquake Disaster

1. The information expected to be acquired

In daily life, when seeking earthquake risk knowledge, the public expects to acquire the following types of information (Figure 2):

- A basic knowledge of earthquakes, including knowledge regarding the causes and types of earthquakes (39.22\%), what the precursors of earthquakes are $(45.56 \%)$, and information about the magnitude and intensity of earthquakes $(17.17 \%)$;

- Earthquake preparedness knowledge, including whether the local area is in an earthquake zone and the historical earthquake occurrences $(45.10 \%)$, guidance regarding of how to stock up on emergency food, medicines and supplies (67.66\%), and information about reinforcing houses, home appliances, and furniture (34.43\%); 
- Earthquake emergency response knowledge, including information about earthquake emergency evacuation (83.74\%), self-help, mutual help and emergency care information during an earthquake $(79.57 \%)$, safe escape route guidance during an earthquake $(44.19 \%)$, and details about nearby safe emergency shelter (49.23\%);

- The earthquake emergency plan formulated by the government $(20.41 \%)$;

- Self-psychological guidance knowledge (5.11\%).

Causes and types of earthquakes

What are the precursors of earthquakes

Magnitude and intensity of earthquakes

Whether the area is in an earthquake zone and historical... How to stock up on emergency food, medicines and supplies

Reinforcing houses, home appliances and furniture Earthquake emergency evacuation Self-help, mutual help and emergency care during an... Safe escape routes during an earthquake Nearby safe emergency shelters Earthquake emergency plan formulated by the government Knowledge of self-psychological guidance None
Other

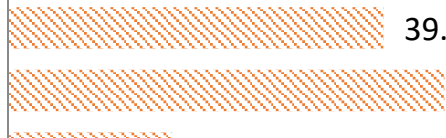

$17.17 \%$
$39.22 \%$

$45.56 \%$

$45.10 \%$

$67.66 \%$
$34.43 \%$

$79.57 \%$

$49.23 \%$

$5.11 \%$

$0.30 \%$

$1.73 \%$

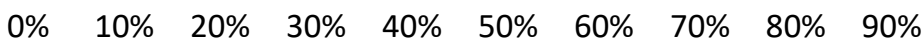 \\ Proportion of people}

Figure 2. Information expected to be acquired by the public in the prodromal stage of an earthquake disaster.

2. The information actually acquired

In daily life, the types of earthquake information actually acquired by the public in daily life are ranked as follows (Figure 3):

Information about earthquake emergency evacuation (54.51\%); guidance regarding how to stock up on emergency food, medicine and supplies (49.24\%); self-help, mutual help and emergency care information during an earthquake (47.24\%); what the precursors of earthquakes are (31.44\%); details about nearby safe emergency shelter $(25.14 \%)$; knowledge regarding the causes and types of earthquakes (24.07\%); information about reinforcing houses, home appliances and furniture (22.45\%); whether the local area is in an earthquake zone and the historical earthquakes occurrences (21.78\%); safe escape route guidance during an earthquake (16.42\%); information about the magnitude and intensity of earthquakes $(9.69 \%)$; the earthquake emergency plans formulated by the government (6.99\%); and self-psychological guidance knowledge (1.16\%).

\section{Information deviation index}

According to the definition of IDI above, it can be seen that, in daily life, the deviation between the information expected and the information actually acquired by the people in the disaster zone presents different characteristics (Table 4). 
Causes and types of earthquakes

What are the precursors of earthquakes

Magnitude and intensity of earthquakes

Whether the area is in an earthquake zone and.. How to stock up on emergency food, medicines and.. Reinforcing houses, home appliances and furniture Earthquake emergency evacuation Self-help, mutual help and emergency care during an... Safe escape routes during an earthquake Nearby safe emergency shelters Earthquake emergency plan formulated by the... Knowledge of self-psychological guidance None
Other

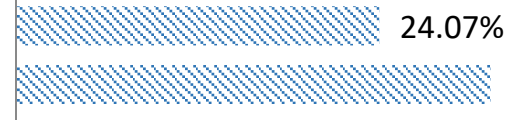

$9.69 \%$
$31.44 \%$

$21.78 \%$

\section{$22.45 \%$}

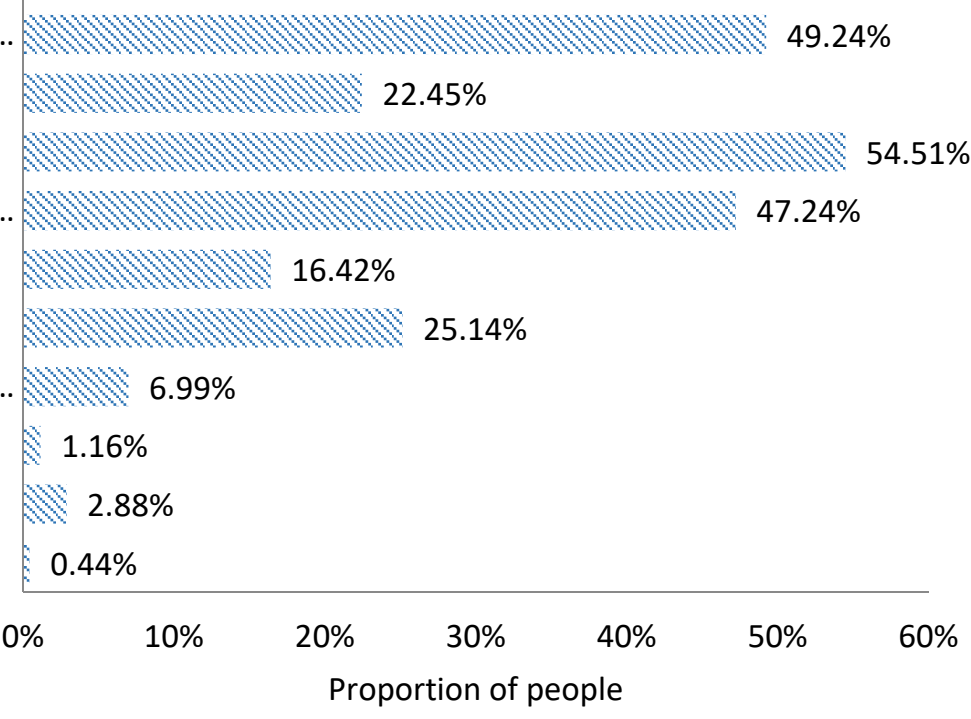

Figure 3. Information actually acquired by the public in the prodromal stage of an earthquake disaster.

The IDI values for self-help, mutual help, and emergency care information during an earthquake and knowledge regarding the causes and types of earthquakes are -0.01 and -0.04 , respectively, both of which are negative values, indicating that the public's expected information on these two indicators is satisfied. The two values tend to be close to 0 , representing that the actual information acquired is close to the expected information acquired. This indicates that the information the people want and the information they finally get are symmetrical. In addition, the IDI values for information about earthquake emergency evacuation; information about reinforcing houses, home appliances, and furniture; what the precursors of earthquakes are; and guidance regarding how to stock up on emergency food, medicines, and supplies are $-0.11,-0.11,-0.17$, and -0.24 , respectively, indicating that the actual information that can be acquired about these four indicators has exceeded the information that people expect to acquire, and that people's expectations can be met. The IDI value of 0.04 for the knowledge regarding the earthquake magnitude and intensity is positive, indicating that the information expected by the public for this indicator has not been met, but the result tends to be close to 0 , indicating that the actual information acquired is close to the expected information. The IDI values for details about nearby safe evacuation sites, whether the local area is in the earthquake zone and the historical earthquake occurrences, safe escape route guidance during an earthquake, the earthquake emergency plans formulated by the government, and knowledge of self-psychological guidance are $0.13,0.18,0.37,0.42$, and 0.61 , respectively, indicating that people's expectations of acquiring the information relating to these five aspects are not satisfied.

\subsubsection{The Acute Stage of an Earthquake Disaster}

1. The information expected to be acquired (Figure 4) is as follows:

- $\quad$ Earthquake information, including the epicenter, magnitude, and spread range (74.23\%), and cause of the earthquake $(48.25 \%)$;

- Disaster information, including the extent of earthquake damage (69.79\%) and personnel casualties $(66.19 \%)$;

- Public psychological reaction information, including whether it endangers the safety of the life and property of oneself or relatives and friends $(70.52 \%)$, whether there is a 
greater danger (59.90\%), what the government is doing $(34.74 \%)$, what I should do $(25.97 \%)$, and whether anyone is coming to save me $(16.08 \%)$;

- Emergency evacuation and shelter information, including safe evacuation routes $(45.46 \%)$ and shelters nearby $(45.36 \%)$.

Epicenter, magnitude, spread range

Cause of the earthquake

Extent of earthquake damage

Personnel casualties

Whether it endangers the safety of the life and property...

Whether there is a greater danger

What the government is doing

What I should do

Whether anyone is coming to save me

Safe evacuation routes

Shelters nearby

None
Other

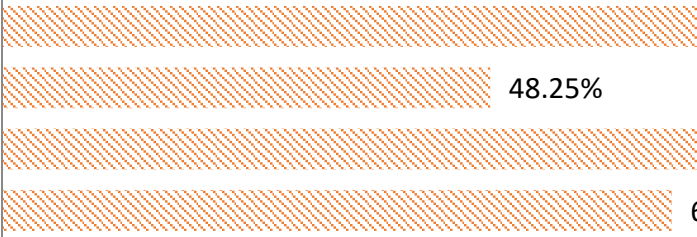

$74.23 \%$

$69.79 \%$

$66.19 \%$

$59.90 \%$

$34.74 \%$

$25.97 \%$

$16.08 \%$

$45.46 \%$

$45.36 \%$

$0.10 \%$

$1.03 \%$

Proportion of people

Figure 4. Information expected to be acquired by the public in the acute stage of an earthquake disaster.

2. The information actually acquired

At the first time of the earthquake, the ranking of the earthquake-related information actually acquired by the public is in order (Figure 5):

Epicenter, magnitude, spread range

Cause of the earthquake

Extent of earthquake damage

Personnel casualties

Whether it endangers the safety of the life and property..

Whether there is a greater danger

What the government is doing

What I should do

Whether anyone is coming to save me

Safe evacuation routes

Shelters nearby

None

Other

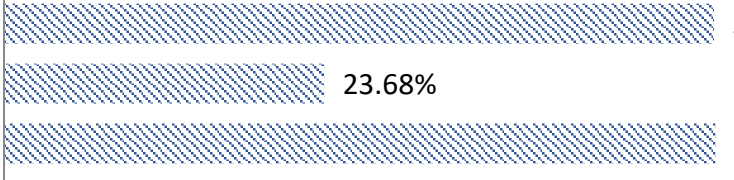

$52.54 \%$

$52.65 \%$

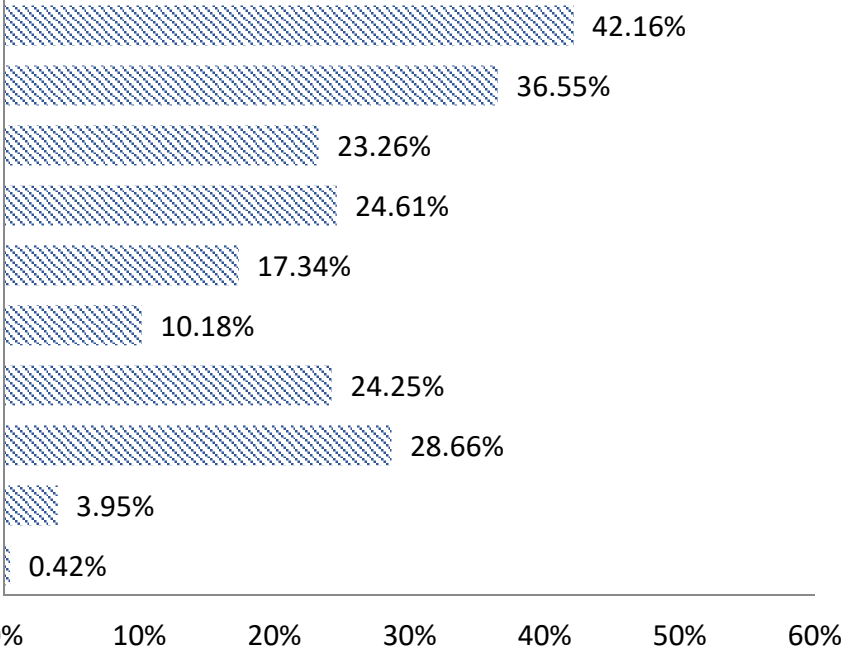

Proportion of people

Figure 5. Information actually acquired by the public in the acute stage of an earthquake disaster. 
Table 4. Information deviation index in the prodromal stage of an earthquake disaster.

\begin{tabular}{|c|c|c|c|c|c|c|c|}
\hline Types & Index & $\begin{array}{c}\text { Expected } \\
\text { Information before } \\
\text { Weighting }\end{array}$ & $\begin{array}{c}\text { Expected } \\
\text { Information after } \\
\text { Weighting }\end{array}$ & $\begin{array}{c}\text { Actual Information } \\
\text { before Weighting }\end{array}$ & $\begin{array}{l}\text { Actual Information } \\
\text { after Weighting }\end{array}$ & IDI & $\begin{array}{c}\text { Information } \\
\text { Content }^{1}\end{array}$ \\
\hline \multirow{3}{*}{$\begin{array}{l}\text { Basic earthquake } \\
\text { knowledge }\end{array}$} & Causes and types of earthquakes & $39.22 \%$ & $7.35 \%$ & $24.07 \%$ & $7.68 \%$ & -0.04 & $\sqrt{ }$ \\
\hline & What are the precursors of earthquakes & $45.56 \%$ & $8.54 \%$ & $31.44 \%$ & $10.03 \%$ & -0.17 & $\sqrt{ }$ \\
\hline & Magnitude and intensity of earthquakes & $17.17 \%$ & $3.22 \%$ & $9.69 \%$ & $3.09 \%$ & 0.04 & $\times$ \\
\hline \multirow{5}{*}{$\begin{array}{l}\text { Earthquake } \\
\text { preparedness } \\
\text { knowledge }\end{array}$} & Whether the local area is in an earthquake & & & & & & \\
\hline & zone and the historical & $45.10 \%$ & $8.45 \%$ & $21.78 \%$ & $6.95 \%$ & 0.18 & $\times$ \\
\hline & earthquake occurrences & & & & & & \\
\hline & $\begin{array}{l}\text { How to stock up on emergency food, } \\
\text { medicines and supplies }\end{array}$ & $67.66 \%$ & $12.68 \%$ & $49.24 \%$ & $15.71 \%$ & -0.24 & $\sqrt{ }$ \\
\hline & $\begin{array}{l}\text { Reinforcing houses, home appliances } \\
\text { and furniture }\end{array}$ & $34.43 \%$ & $6.45 \%$ & $22.45 \%$ & $7.16 \%$ & -0.11 & $\sqrt{ }$ \\
\hline \multirow{9}{*}{$\begin{array}{c}\text { Earthquake } \\
\text { emergency response } \\
\text { knowledge }\end{array}$} & Earthquake emergency evacuation & $83.74 \%$ & $15.70 \%$ & $54.51 \%$ & $17.39 \%$ & -0.11 & $\sqrt{ }$ \\
\hline & Self-help, mutual help and emergency care & $79.57 \%$ & $14.92 \%$ & $47.24 \%$ & $15.07 \%$ & -0.01 & $\sqrt{ }$ \\
\hline & Safe escape routes during an earthquake & $44.19 \%$ & $8.28 \%$ & $16.42 \%$ & $5.24 \%$ & 0.37 & $\times$ \\
\hline & Nearby safe emergency shelter & $49.23 \%$ & $9.23 \%$ & $25.14 \%$ & $8.02 \%$ & 0.13 & $\times$ \\
\hline & $\begin{array}{l}\text { Earthquake emergency plan formulated by } \\
\text { the government }\end{array}$ & $20.41 \%$ & $3.83 \%$ & $6.99 \%$ & $2.23 \%$ & 0.42 & $\times$ \\
\hline & Self-psychological guidance & $5.11 \%$ & $0.96 \%$ & $1.16 \%$ & $0.37 \%$ & 0.61 & $\times$ \\
\hline & None & $0.30 \%$ & $0.06 \%$ & $2.88 \%$ & $0.92 \%$ & -14.33 & $\sqrt{ }$ \\
\hline & Other & $1.73 \%$ & $0.32 \%$ & $0.44 \%$ & $0.14 \%$ & 0.56 & $\times$ \\
\hline & Total & $533.42 \%$ & $100.00 \%$ & $313.45 \%$ & $100.00 \%$ & $\longrightarrow$ & $\longrightarrow$ \\
\hline
\end{tabular}

${ }^{1} \sqrt{ }$ represents satisfaction; $\times$ means unsatisfactory. 
The extent of earthquake damage (52.65\%); and earthquake epicenter, magnitude, and spread range (52.54\%); personnel casualties $(42.16 \%)$; whether it endangers the safety of the life and property of oneself or relatives and friends (36.55\%); shelters nearby $(28.66 \%)$; what the government is doing $(24.61 \%)$; safe evacuation routes $(24.25 \%)$; causes of the earthquake (23.68\%); whether there is a greater danger $(23.26 \%)$; what I should do $(17.34 \%)$; and whether anyone is coming to save me $(10.18 \%)$.

3. Information deviation index

According to the definition of IDI above, it can be seen that, in the first period after an earthquake, the deviation between the information expected by the people in the disaster area and the information actually acquired presents different characteristics (Table 5).

The IDI value regarding safe evacuation routes is 0 , which means that the information people want to receive about safe evacuation routes and the information they finally receive are symmetrical. The IDI values regarding shelters nearby, whether anyone is coming to save me, personnel casualties, and what I should do are $-0.02,-0.02,-0.03$, and -0.08 , respectively, which are negative values, indicating that people's expectations of information about these four indicators are met. An IDI value tending to be 0 proves that the actual information is close to the expectation. In addition, the IDI value concerning the extent of earthquake damage, the information on the magnitude, and extent of the earthquake and the information on what the government is doing are $-0.22,-0.15$, and -0.15 , respectively, indicating that people's expectations about these three indicators can be met. The IDI values with regard to whether there is a greater danger and the cause of the earthquake are 0.37 and 0.20 , respectively, indicating that people's expectations of acquiring information about these two aspects have not been met.

\subsubsection{The Chronic Stage of an Earthquake Disaster}

1. The information expected to be acquired

During the earthquake relief period, the earthquake disaster information that people in the disaster area expect to acquire is as follows (Figure 6):

- $\quad$ Earthquake information, including information on aftershocks (75.43\%);

- Disaster information, including personnel casualties (73.80\%), property losses (30.44\%), secondary disasters $(25.70 \%)$, and infectious diseases (33.44\%);

- Real-time progress information on disaster relief and rescue, including personnel rescue $(59.54 \%)$, the resettlement of victims $(60.99 \%)$, and the restoration of transportation and communication (45.41\%);

- Relief supplies and donations information, including the distribution of relief supplies $(51.81 \%)$ and social relief and donations (32.40\%);

- Domestic and foreign media reported information, including reports on volunteers $(16.20 \%)$, medical assistance $(30.65 \%)$, and disaster relief troops $(21.98 \%)$.

2. The information actually acquired

In the earthquake relief period, the information actually acquired by the victims is ranked as follows (Figure 7): information on aftershocks (52.78\%), personnel casualties $(51.03 \%)$, resettlement of victims $(46.60 \%)$, personnel rescue $(41.24 \%)$, distribution of relief supplies $(36.91 \%)$, the restoration of transportation and communication $(29.79 \%)$, social relief and donations $(23.71 \%)$, property losses $(22.37 \%)$, reports on medical assistance $(20.41 \%)$, reports on disaster relief troops $(19.48 \%)$, infectious diseases $(14.43 \%)$, reports on volunteers $(14.33 \%)$, and secondary disasters $(13.71 \%)$.

\section{Information deviation index}

According to the IDI definition above, it can be seen that, during the earthquake relief period, the deviation between the information expected by the people in the disaster area and the information actually acquired shows different characteristics (Table 6). 
Table 5. Information deviation index in the acute stage of an earthquake disaster.

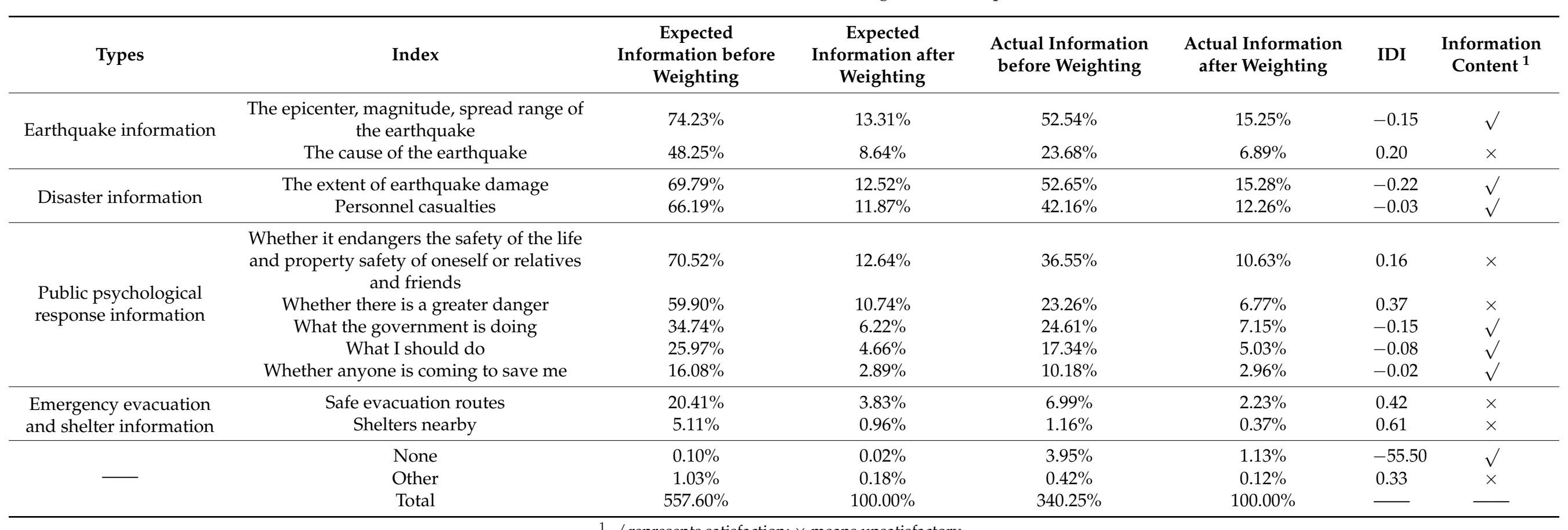

${ }^{1} \sqrt{ }$ represents satisfaction; $\times$ means unsatisfactory. 
Information on aftershocks

Personnel rescue

Personnel casualties

Resettlement of victims

Restoration of transportation and communication

Distribution of relief supplies

Social relief and donations

Property losses

Secondary disasters

Infectious diseases

Reports on volunteers

Reports on medical assistance

Reports on disaster relief troops

None
Other

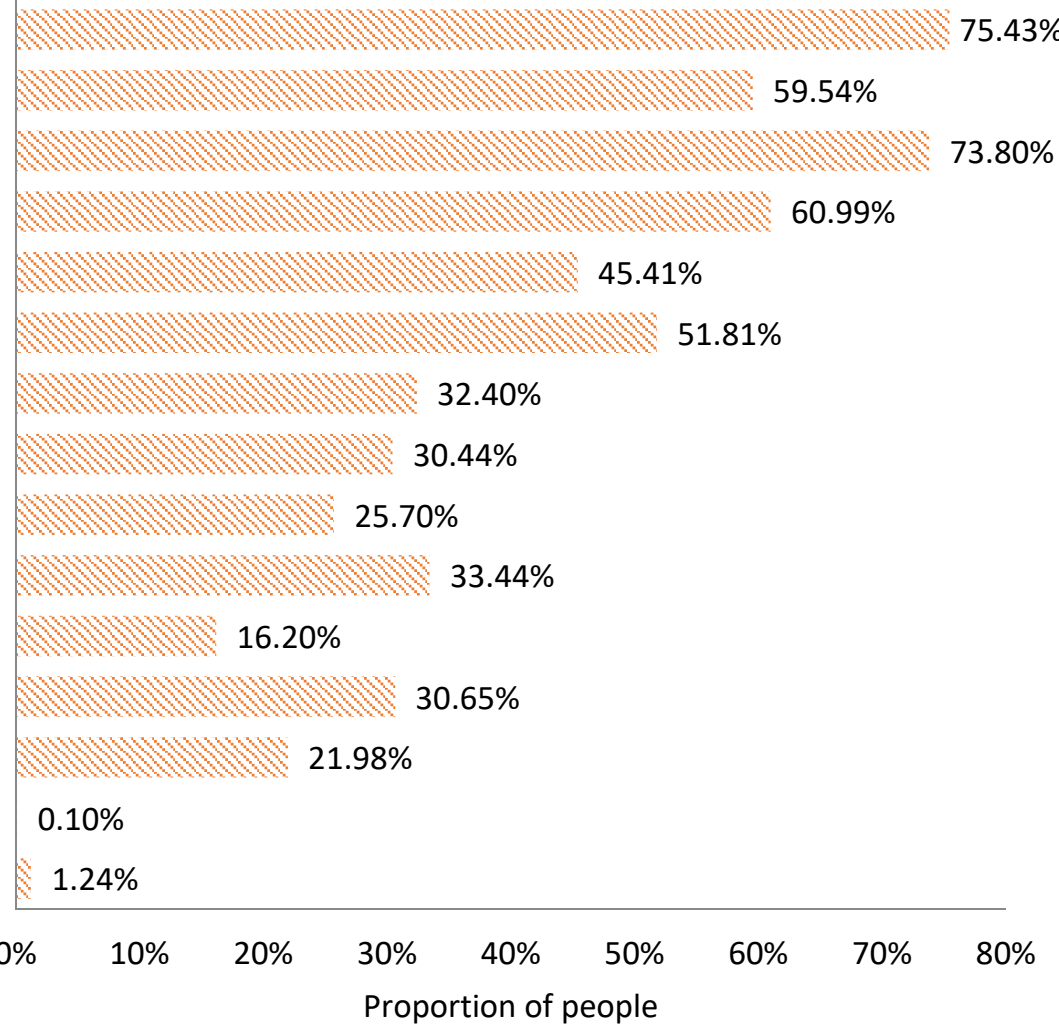

$75.43 \%$ 
Table 6. Information deviation index in the chronic stage of an earthquake disaster.

\begin{tabular}{|c|c|c|c|c|c|c|c|}
\hline Types & Index & $\begin{array}{c}\text { Expected } \\
\text { Information before } \\
\text { Weighting }\end{array}$ & $\begin{array}{l}\text { Expected } \\
\text { Information after } \\
\text { Weighting }\end{array}$ & $\begin{array}{l}\text { Actual Information } \\
\text { before Weighting }\end{array}$ & $\begin{array}{l}\text { Actual Information } \\
\text { after Weighting }\end{array}$ & IDI & $\begin{array}{l}\text { Information } \\
\text { Content }^{1}\end{array}$ \\
\hline Earthquake information & Information on aftershocks & $75.43 \%$ & $13.49 \%$ & $52.78 \%$ & $13.42 \%$ & 0.00 & $\sqrt{ }$ \\
\hline \multirow{4}{*}{ Disaster information } & Personnel casualties & $73.80 \%$ & $13.20 \%$ & $51.03 \%$ & $12.98 \%$ & 0.02 & $x$ \\
\hline & Property losses & $30.44 \%$ & $5.44 \%$ & $22.37 \%$ & $5.69 \%$ & -0.05 & $\sqrt{ }$ \\
\hline & Secondary disasters & $25.70 \%$ & $4.60 \%$ & $13.71 \%$ & $3.49 \%$ & 0.24 & $\times$ \\
\hline & Infectious diseases & $33.44 \%$ & $5.98 \%$ & $14.43 \%$ & $3.67 \%$ & 0.39 & $\times$ \\
\hline \multirow{2}{*}{$\begin{array}{l}\text { Real-time progress } \\
\text { information on disaster relief } \\
\text { and rescue }\end{array}$} & Resettlement of victims & $60.99 \%$ & $10.91 \%$ & $46.60 \%$ & $11.85 \%$ & -0.09 & $\sqrt{ }$ \\
\hline & $\begin{array}{l}\text { The restoration of transportation } \\
\text { and communication }\end{array}$ & $45.41 \%$ & $8.12 \%$ & $29.79 \%$ & $7.58 \%$ & 0.07 & $\times$ \\
\hline \multirow{2}{*}{$\begin{array}{l}\text { Relief supplies and } \\
\text { donations information }\end{array}$} & Distribution of relief supplies & $51.81 \%$ & $9.27 \%$ & $36.91 \%$ & $9.39 \%$ & -0.01 & $\sqrt{ }$ \\
\hline & Social relief and donations & $32.40 \%$ & $5.80 \%$ & $23.71 \%$ & $6.03 \%$ & -0.04 & $\sqrt{ }$ \\
\hline \multirow{5}{*}{$\begin{array}{l}\text { Domestic and foreign media } \\
\text { reported information }\end{array}$} & Reports on volunteers & $16.20 \%$ & $2.90 \%$ & $14.33 \%$ & $3.64 \%$ & -0.26 & $\sqrt{ }$ \\
\hline & Reports on medical assistance & $30.65 \%$ & $5.48 \%$ & $20.41 \%$ & $5.19 \%$ & 0.06 & $\times$ \\
\hline & Reports on disaster relief troops & $21.98 \%$ & $3.93 \%$ & $19.48 \%$ & $4.95 \%$ & -0.26 & $\sqrt{ }$ \\
\hline & Other & $1.24 \%$ & $0.22 \%$ & $0.93 \%$ & $0.24 \%$ & -0.07 & $\sqrt{ }$ \\
\hline & Total & $559.13 \%$ & $100.00 \%$ & $393.20 \%$ & $100.00 \%$ & - & . \\
\hline
\end{tabular}


The IDI value of information on aftershocks is 0 , which shows that the information people want regarding aftershocks and the information they finally receive are symmetrical. The IDI values of personnel rescue, personnel casualties, reports on medical assistance, and the restoration of transportation and communication are $0.02,0.02,0.06$, and 0.07 , respectively, which are all positive, indicating that people's expected information about these four indicators is not satisfied. However, the results tend to be close to 0 , indicating that the information actually acquired is close to the expected information. The IDI values of information on the distribution of relief supplies, social relief and donations, property losses, and the resettlement of victims are $-0.01,-0.04,-0.05$, and -0.09 , respectively, which are all negative, indicating that people's expected information on these four indicators is satisfied and the result is close to 0 , also indicating that the actual information acquired is close to the expected information acquired. In addition, the IDI values of secondary disasters and infectious diseases are 0.24 and 0.39 , respectively, indicating that the public's expectation of acquiring relevant information about these two aspects has not been met. The IDI values of reports on volunteers and disaster relief troops are -0.26 and -0.26 , indicating that the information available on these two aspects has exceeded the expectations of the public, and that the expectations of the public can be met.

\subsubsection{The Resolution Stage of an Earthquake Disaster}

1. The information expected to be acquired

During the post-disaster reconstruction period, the information that people in the disaster area expect to acquire is divided into the following categories (Figure 8):

- Post-disaster reconstruction plan (70.97\%);

- Implementation of social donations and relief supplies $(58.06 \%)$;

- The situation of disaster victims, including the living conditions of the affected people $(69.11 \%)$, the compensation for disaster losses (46.18\%), the learning and living conditions of children in the disaster area $(64.77 \%)$, and the resettlement of orphans in the disaster area $(51.96 \%)$;

- The situation in the disaster area, including the economic recovery in the disaster area $(39.36 \%)$.

Post-disaster reconstruction plan

Implementation of social donations and relief supplies

Living conditions of the affected people

Compensation for disaster losses

Learning and living conditions of children in the disaster...

Resettlement of orphans in the disaster area

Economic recovery in the disaster area

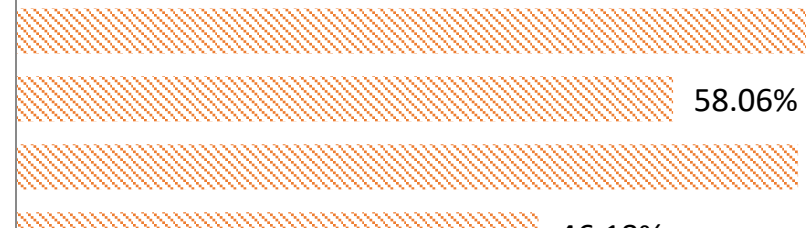

$70.97 \%$

$8.06 \%$

$69.11 \%$

$46.18 \%$

$64.77 \%$

$51.96 \%$

No concern

None

Other

$2.38 \%$

\begin{tabular}{|c|c|c|c|c|c|c|c|}
\hline $0 \%$ & $10 \%$ & $20 \%$ & $30 \%$ & $40 \%$ & $50 \%$ & $60 \%$ & $70 \%$ \\
\hline
\end{tabular}

Figure 8. Information expected to be acquired by the public in the resolution stage of an earthquake disaster.

2. The information actually acquired 
During the post-disaster reconstruction period, the actual information acquired by the people in the disaster area is sorted as follows (Figure 9): the living conditions of the affected people $(44.72 \%)$, the implementation of social donations and relief supplies $(39.96 \%)$, the learning and living conditions of children in the disaster-hit areas $(39.86 \%)$, the post-disaster reconstruction plan (39.54\%), the resettlement of orphans in the disaster area $(30.54 \%)$, the economic recovery in the disaster area $(30.02 \%)$, and the compensation for disaster losses $(29.61 \%)$.

Post-disaster reconstruction plan

Implementation of social donations and relief supplies

Living conditions of the affected people

Compensation for disaster losses

Learning and living conditions of children in the disaster...

Resettlement of orphans in the disaster area

Economic recovery in the disaster area

No concern

None

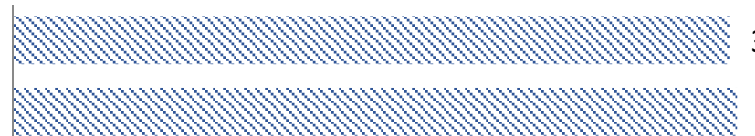

$39.54 \%$

$39.96 \%$

$44.72 \%$

$29.61 \%$

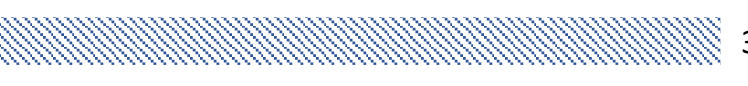

$39.86 \%$

$30.02 \%$

$10.25 \%$

$7.97 \%$

$4.76 \%$

$5 \% \quad 10 \% \quad 15 \% \quad 20 \% \quad 25 \% \quad 30 \% \quad 35 \% \quad 40 \% \quad 45 \% \quad 50 \%$

Proportion of people

Figure 9. Information actually acquired by the public in the resolution stage of an earthquake disaster.

\section{Information deviation index}

According to the above definition of IDI, it can be seen that, during the earthquake disaster recovery period, the deviation between the expected information and the actual information acquired by the people in disaster areas presents different characteristics (Table 7).

The information deviation index values of the information regarding the living conditions of the affected people, the compensation for disaster losses, and the learning and living conditions of children in the affected area are $0.04,0.05$, and 0.09 , respectively, all of which are positive, indicating that people's expected information regarding these three indicators could not be satisfied; however, the results tend to be close to 0 , suggesting that the actually acquired information is close to the expected information. The IDI value of the information on the implementation of social donations and disaster relief supplies is -0.02 and negative, indicating that people's expectations of the indicator has been met and approach 0 , indicating that the actual information acquired is close to the expected information. In addition, the IDI values of the post-disaster reconstruction plan and the resettlement of orphans in the disaster areas are 0.18 and 0.13 , respectively, indicating that people's expectations of acquiring relevant information on these two aspects have not been met. Moreover, the IDI value of information about the economic recovery in the disaster area is -0.13 , which indicates that the information about this area is actually more available than people expect; thus, the people's expectations can be met. 
Table 7. Information deviation index in the resolution stage of an earthquake disaster.

\begin{tabular}{|c|c|c|c|c|c|c|}
\hline Index & $\begin{array}{l}\text { Expected Information } \\
\text { before Weighting }\end{array}$ & $\begin{array}{l}\text { Expected Information } \\
\text { after Weighting }\end{array}$ & $\begin{array}{l}\text { Actual Information } \\
\text { before Weighting }\end{array}$ & $\begin{array}{l}\text { Actual Information } \\
\text { after Weighting }\end{array}$ & IDI & Information Content ${ }^{1}$ \\
\hline Post-disaster reconstruction plan & $70.97 \%$ & $17.32 \%$ & $39.54 \%$ & $14.26 \%$ & 0.18 & $x$ \\
\hline $\begin{array}{l}\text { Implementation of social donations } \\
\text { and relief supplies }\end{array}$ & $58.06 \%$ & $14.17 \%$ & $39.96 \%$ & $14.41 \%$ & -0.02 & $\sqrt{ }$ \\
\hline Living conditions of the affected people & $69.11 \%$ & $16.87 \%$ & $44.72 \%$ & $16.13 \%$ & 0.04 & $x$ \\
\hline The compensation for disaster losses & $46.18 \%$ & $11.27 \%$ & $29.61 \%$ & $10.68 \%$ & 0.05 & $x$ \\
\hline $\begin{array}{l}\text { The learning and living conditions of } \\
\text { children in the disaster area }\end{array}$ & $64.77 \%$ & $15.81 \%$ & $39.86 \%$ & $14.38 \%$ & 0.09 & $\times$ \\
\hline The economic recovery in the disaster area & $39.36 \%$ & $9.61 \%$ & $30.02 \%$ & $10.83 \%$ & -0.13 & $\sqrt{ }$ \\
\hline No concern & $6.51 \%$ & $1.59 \%$ & $10.25 \%$ & $3.70 \%$ & -1.33 & $\sqrt{ }$ \\
\hline None & $0.41 \%$ & $0.10 \%$ & $7.97 \%$ & $2.87 \%$ & -27.73 & $\sqrt{ }$ \\
\hline Other & $2.38 \%$ & $0.58 \%$ & $4.76 \%$ & $1.72 \%$ & -1.96 & $\sqrt{ }$ \\
\hline Total & $409.71 \%$ & $100.00 \%$ & $277.23 \%$ & $100.00 \%$ & - & - \\
\hline
\end{tabular}

${ }^{1} \sqrt{ }$ represents satisfaction; $\times$ means unsatisfactory. 


\subsubsection{Main Risk Information Composition of in Different Stages of an Earthquake Disaster}

Based on the above research, the composition of the main risk information on earthquake disasters is in different stages, as shown in Figure 10. In other words, in the prodromal stage of an earthquake disaster, earthquake risk management should focus on disaster identification, disaster prevention, and disaster preparation. At this time, the main risk information should include earthquake-related basic knowledge, earthquake preparation knowledge, and earthquake emergency knowledge. In the acute stage of an earthquake disaster, earthquake risk management should focus on disaster early warning, disaster response, and emergency disposal, while the risk information released should mainly include earthquake information, disaster information, public psychological reaction information, and emergency evacuation and shelter information. In the chronic stage of an earthquake disaster, earthquake risk management should focus on disaster response, emergency disposal, and emergency rescue, while the risk information at this time should mainly be earthquake information, disaster information, real-time progress information on disaster relief and rescue, relief supplies and donations information, and domestic and foreign media information. In the recovery stage of an earthquake disaster, earthquake risk management should mainly be focused on the post-disaster treatment and post-disaster recovery and reconstruction, while the risk information at this time should focus on the post-disaster reconstruction plan, information about the implementation of social donations and relief supplies, information about the victims, and information about the disaster area.

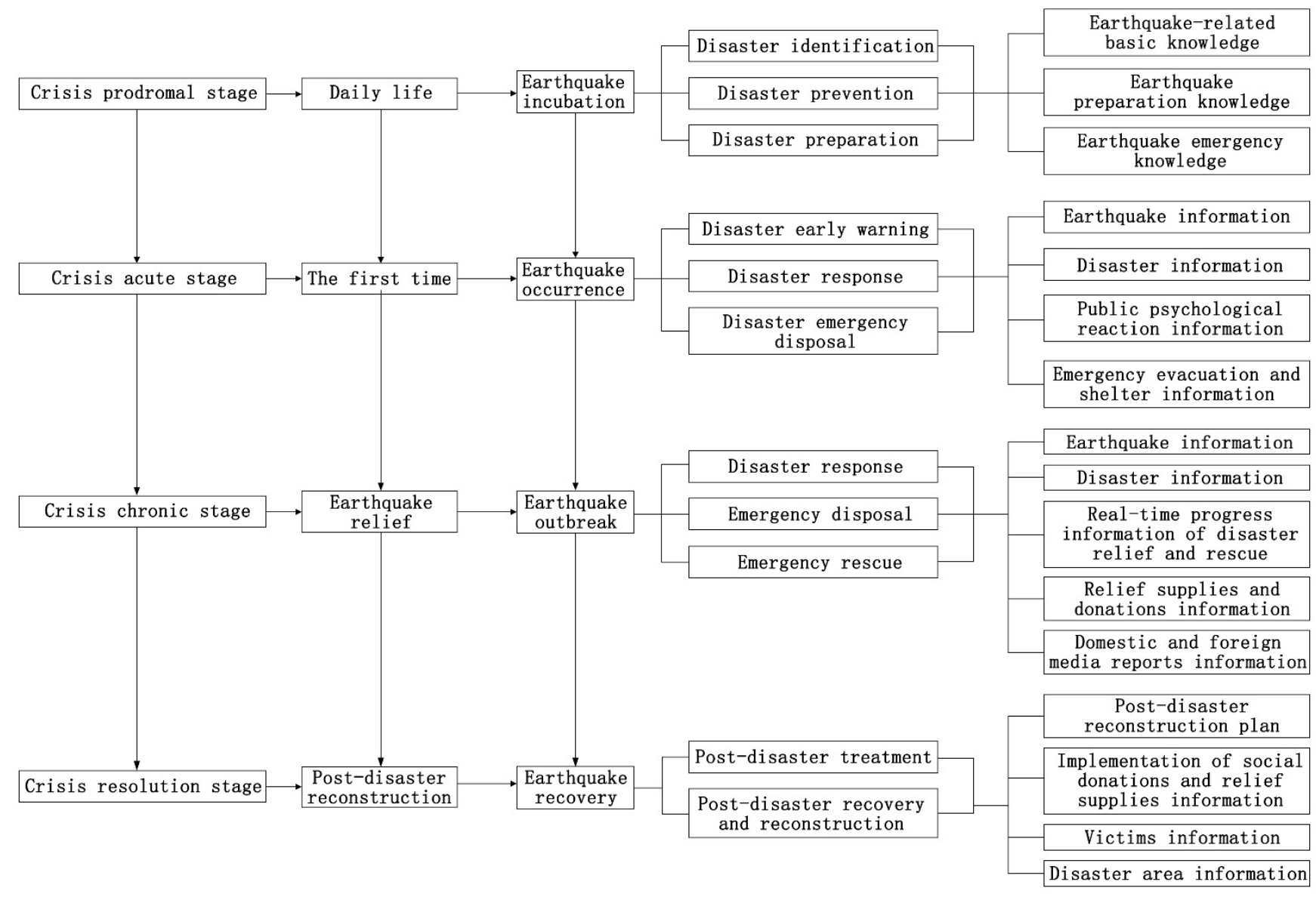

Figure 10. Main information composition in the different stages of an earthquake disaster. 


\subsection{Information Communication Channel Preferences of Earthquake Disaster}

\subsubsection{The Prodromal Stage of an Earthquake Disaster}

In daily life, $74.22 \%$ of the respondents acquire earthquake-related knowledge and information through TV reports, which indicates that TV, as a traditional media, still plays a pivotal role in the dissemination of earthquake knowledge and information. The second most common channel is the internet, accounting for $53.76 \%$, which also illustrates the indispensable role of the internet as a new medium in risk communication. The third most common channel is interpersonal communication, with $40.81 \%$ of respondents believing that interpersonal communication is the easiest and fastest way to acquire earthquake disaster information and knowledge. Radio broadcasts (33.19\%), newspapers and magazines $(20.04 \%)$, and mobile phone text messages $(19.73 \%)$ also proved to be effective means of communication (shown in Table 8).

Table 8. Information communication channel preferences in the different stages of an earthquake disaster.

\begin{tabular}{|c|c|c|c|c|c|c|c|c|}
\hline Types & $\begin{array}{l}\text { Prodromal } \\
\text { Stage before } \\
\text { Weighting }\end{array}$ & $\begin{array}{l}\text { Prodromal } \\
\text { Stage after } \\
\text { Weighting }\end{array}$ & $\begin{array}{c}\text { Acute Stage } \\
\text { before } \\
\text { Weighting }\end{array}$ & $\begin{array}{c}\text { Acute Stage } \\
\text { after } \\
\text { Weighting }\end{array}$ & $\begin{array}{c}\text { Chronic Stage } \\
\text { before } \\
\text { Weighting }\end{array}$ & $\begin{array}{c}\text { Chronic Stage } \\
\text { after } \\
\text { Weighting }\end{array}$ & $\begin{array}{l}\text { Resolution } \\
\text { Stage before } \\
\text { Weighting }\end{array}$ & $\begin{array}{l}\text { Resolution } \\
\text { Stage after } \\
\text { Weighting }\end{array}$ \\
\hline TV & $74.22 \%$ & $30.57 \%$ & $61.24 \%$ & $33.48 \%$ & $55.77 \%$ & $30.07 \%$ & $55.28 \%$ & $30.07 \%$ \\
\hline Radio broadcasts & $33.19 \%$ & $13.67 \%$ & $17.32 \%$ & $9.47 \%$ & $22.47 \%$ & $12.12 \%$ & $19.36 \%$ & $12.12 \%$ \\
\hline $\begin{array}{l}\text { Newspapers and } \\
\text { magazines }\end{array}$ & $20.04 \%$ & $8.26 \%$ & $10.10 \%$ & $5.52 \%$ & $17.73 \%$ & $9.56 \%$ & $16.77 \%$ & $9.56 \%$ \\
\hline The Internet & $53.76 \%$ & $22.14 \%$ & $42.99 \%$ & $23.50 \%$ & $41.44 \%$ & $22.34 \%$ & $42.55 \%$ & $22.34 \%$ \\
\hline $\begin{array}{l}\text { Mobile phone } \\
\text { text messages }\end{array}$ & $19.73 \%$ & $8.13 \%$ & $23 \%$ & $12.58 \%$ & $20.62 \%$ & $11.12 \%$ & $16.15 \%$ & $11.12 \%$ \\
\hline $\begin{array}{l}\text { Interpersonal } \\
\text { communication }\end{array}$ & $40.81 \%$ & $16.81 \%$ & $24.33 \%$ & $13.30 \%$ & $21.34 \%$ & $11.51 \%$ & $23.19 \%$ & $11.51 \%$ \\
\hline None & $1.04 \%$ & $0.43 \%$ & $0.93 \%$ & $0.51 \%$ & $2.58 \%$ & $1.39 \%$ & $1.14 \%$ & $1.39 \%$ \\
\hline Other & $0 \%$ & $0.00 \%$ & $2.99 \%$ & $1.63 \%$ & $3.51 \%$ & $1.89 \%$ & $3.93 \%$ & $1.89 \%$ \\
\hline Total & $242.79 \%$ & $100.00 \%$ & $182.90 \%$ & $100.00 \%$ & $185.46 \%$ & $100.00 \%$ & $178.37 \%$ & $100.00 \%$ \\
\hline
\end{tabular}

\subsubsection{The Acute Stage of an Earthquake Disaster}

At the first time of the earthquake, people in the earthquake area have obvious preference when they choose information acquisition channels. The usage rates of different channels vary greatly, with more than $60 \%$ of people still preferring TV media $(61.24 \%)$ as a channel to acquire earthquake-related information, and more than $40 \%$ of people choosing the internet $(42.99 \%)$. While fewer people choose newspapers and magazines $(10.10 \%)$, probably because newspapers and magazines have a long production cycles and weak timeliness, and when an earthquake has just occurred, people urgently need to know about the earthquake, so fewer people choose newspapers and magazines to get information. People who choose interpersonal communication, mobile phone text messages, and radio broadcasts account for $24.33 \%, 23.00 \%$, and $17.32 \%$, respectively (as shown in Table 8).

\subsubsection{The Chronic Stage of an Earthquake Disaster}

During the earthquake relief period, TV, as the "first media", still reflects its important position and role in information dissemination, accounting for $55.77 \%$. Moreover, the internet, for its convenience and strong interactivity, has also become the information communication medium and information acquisition channel relied on by the public, accounting for $41.44 \%$. Radio broadcasts, interpersonal communication, and mobile phone text messages play similar roles in the spreading period of earthquake disaster, accounting for $22.47 \%, 21.34 \%$, and $20.62 \%$, respectively, while newspapers and magazines are the lowest, accounting for $17.73 \%$ (shown in Table 8).

\subsubsection{The Resolution Stage of an Earthquake Disaster}

During the post-disaster reconstruction period, more than half of the respondents still choose to use television (55.28\%) to acquire earthquake-related information, followed closely by media, such as the internet $(42.55 \%)$, interpersonal communication $(23.19 \%)$, radio broadcasts $(19.36 \%)$, newspapers and magazines $(16.77 \%)$, and mobile phone text messages $(16.15 \%)$ (shown in Table 8$)$. 


\section{Discussion}

There were two objectives in this research. The first focused on individuals' information needs and communication preferences. Two questions were examined concerning what information content is needed and how this information should be disseminated.

With regard to the "what" question, descriptive statistics revealed that individuals" information needs are highly differentiated at the different stages of an earthquake. Before an earthquake occurrence, individuals are mainly concerned with earthquake disaster preparedness and response knowledge. For example, the top three expected information are knowledge about earthquake emergency evacuation; knowledge regarding self-help, mutual help, and emergency care during an earthquake; and knowledge of how to stock up on emergency food, medicines, and supplies. In the first period after an earthquake occurrence, it can be seen that the public is eager to acquire basic information related to the earthquake disaster itself and information related to their own interests, which is consistent with the results of previous studies $[30,66]$. It can also be seen that, during an earthquake relief period, people in the earthquake zone are firstly concerned about earthquake information and disaster information, and then concerned about real-time progress information on disaster relief and rescue, which confirms previous reports $[30,66]$. During an earthquake disaster recovery period, the public in the earthquake zone is most concerned with the post-disaster reconstruction plan formulated by the government, which is consistent with previous study results $[30,66]$. Evidently, individuals show a shift in information needs from "preparedness and response knowledge" to "disaster information", then to "disaster information and disaster relief information" in parallel, to "reconstruction and reflection information".

In addition, as mentioned above, previous studies on earthquake emergency disaster information classification are missing information classification for the period before an earthquake; therefore, this has been added to this study and divided into basic earthquake knowledge, preparedness knowledge, and emergency response knowledge. Moreover, earthquake damage information in previous studies [20-24] mainly focused on information regarding the direct damage caused by earthquakes, and neglected information on the indirect damage caused by earthquakes (i.e., the psychological impact of earthquakes on the public), which this study includes.

Regarding the "how" question, respondents were asked about previously used and preferred communication channels for the dissemination of earthquake information. As indicated in previous studies [26,42-44], the TV and the internet are the most effective channels. However, the range of internet channels is very wide, and may include search engines, forums, posting, social media, etc. This paper does not make a distinction between these internet channels, which may be a topic for a future in-depth study, particularly the use of social media. In addition, smartphone apps [44,79-81] have now become an important information dissemination channel. These apps are not explored in this paper but may be studied in depth in the future.

In addition to the "what" question and the "how" question, there is another question that needs to be answered-the "when" question, i.e., when this information should be disseminated. This is another area for future research.

With regard to the second research objective, an information deviation index indicator was developed to evaluate the difference between information need and information supply. We used the information expected to be acquired as a representative of information need, and used the information actually acquired as a representative of information supply. There may be room for a certain amount of error, especially between the information supply and the information actually acquired.

In addition to the research objectives, the data acquisition method is also worth discussing. The data of this study were obtained from field investigation. Field investigation revealed disaster information needs in detail, but the timeliness and regional range of acquiring disaster information were limited [82]. Future methods of acquiring data may consider combining field investigation with big data mining, such as using data extracted 
from social media [24,83-91], Google Trends [92,93], and Baidu Index [94,95]. In particular, these several data sources can make it possible to quite easily track the behavior of Internet users in real time. For example, disaster managers can benefit from these tools in the "acute stage" to plan targeted information and communication campaigns, thus increasing their usefulness.

\section{Conclusions}

This research investigated the information content and communication channel preferences from individuals' needs perspective within the setting of earthquake disaster in Chinese society. Compared to a survey of respondents of a place only potentially vulnerable to a risk, the survey presented to the victims of an earthquake stricken area, and provided more realistic and persuasive results. Next, it proposed the main composition of information at the different stages of an earthquake disaster, and clarified which types of earthquake disaster risk information should be given priority at each stage. Moreover, this research developed an IDI to evaluate the efficiency of information supply at each stage based on whether the respondents' information needs are being met, which made up the assessment method of risk communication effectiveness. The research can be replicated in other areas subject to seismic risk, and the policymakers can benefit from the results of this research, as the research draws the following guidance on earthquake risk management.

1. In the prodromal stage, risk management should give priority to the identification, prevention and preparation for earthquake disaster. First, risk management efforts should publicize and popularize knowledge of safety precautions (including basic earthquake-related knowledge and emergency knowledge), help people to establish crisis concepts, mitigate their sense of hardship, assist people to master the skills of self-help and mutual help when faced with an earthquake, and improve their ability to cope with a crisis. Second, risk management work should establish and improve the early warning systems for earthquake disaster, and prepare the public for upcoming earthquake crises; thus, the risk information should include knowledge about preparedness. Third, risk management tasks should include preparing a good earthquake emergency plan in advance.

2. In the acute stage, risk management should focus on early warning, response, and emergency disposal. First, risk communication should include releasing earthquake disaster early warning information to the public in a timely fashion as accurately as possible. Second, risk communication should include an overview of the earthquake, the disaster and its development trend information. Third, risk communication should involve the release of emergency disposal information, such as public psychological reaction information, and emergency evacuation and shelter information.

3. In the chronic stage, earthquake risk management should focus on disaster response, emergency disposal, and emergency rescue. First, earthquake and disaster information should be reported to the public in a timely and comprehensive manner. Second, real-time progress information on disaster relief and rescue, and information on relief supplies and donations should be accurate and objective. Third, risk communication should concentrate on the domestic and foreign media reported information, particularly the reports on volunteers, medical assistance, and disaster relief troops. These positive reports can inspire people's morale and boost their confidence. Fourth, pamphlets should be prepared to help the public with guidance on psychological and adjustment.

4. In the resolution stage, earthquake risk management should concentrate on postdisaster treatment and post-disaster recovery and reconstruction, while encouraging people to be self-reliant, overcome difficulties, rebuild scientifically, restore normal production and living order, and eliminate the impact of the crisis. Therefore, risk information at this time should focus on the post-disaster reconstruction plan, information about the implementation of social donations and relief supplies, information about the victims, and information about the disaster area. 
5. Using the IDI to evaluate the information supply by official information sources at each stage, we found that most of the public's information needs are met, with a few exceptions. Indicators such as, in daily life, information about safe evacuation sites nearby, safe escape routes during an earthquake, the earthquake emergency plans formulated by the government, and knowledge of psychological guidance are not met. This suggests that the governments should include these categories when releasing information in the future.

6. Through an analysis of the communication channel preferences for earthquake disaster information at each stage, it is concluded that the two most prominent information acquisition channels are television and the internet, with radio broadcasts, interpersonal communication, newspapers and magazines, and mobile phone SMS also being effective communication channels. Therefore, when releasing earthquake disaster information in the future, it is recommended that the priority dissemination channels should be the TV and the internet.

In viewing these results, some limitations of this research should be explained.

(a) The study area was an earthquake-stricken area. Further research should add non-earthquake areas as the study area to compare whether there are differences between the two areas regarding the residents' earthquake disaster information preferences.

(b) The elderly and younger social groups were missing from the respondents group in this study, and these groups are very vulnerable during such disasters. In this research, $3 \%$ of respondents were aged over 60 years, and there were no respondents below the age of 14 . To date, few studies have investigated the risk information needs of the elderly and the young; this should be an area of interest for future research.

(c) This information preference research focuses on information content and communication channel preferences. In future, the study of information expression could be deepened by exploring the accessibility and ease of use of information, i.e., the type of information presentation formats (e.g., text, image, video) used by people to access and utilize information.

Supplementary Materials: The following are available online at https:/ /www.mdpi.com/article/ 10.3390/ijerph182413070/s1, Supplementary File S1: Survey on earthquake disaster information content and acquisition channels.

Author Contributions: S.L. and R.P. developed the original idea and contributed to the conceptual framework; S.L. and R.P. wrote the paper and were responsible for data collection, process and analysis; X.P. completed the charting; Z.S. finished the English corrections; L.L. and H.Y. provided improving suggestions. All authors have read and agreed to the published version of the manuscript.

Funding: This research was funded by the Liaoning Planning Fund Project of Philosophy and Social Science, grant number L20CGL004, the National Natural Science Foundation of China, grant number 41871162, and the Fundamental Research Funds for the Central Universities, grant number N182410002-5 and N2011001.

Institutional Review Board Statement: Ethical review and approval were waived for this study. We are very sorry that there is no ethics committee in my workplace, nor is there an organization that can provide this service. However, please be assured that ethical requirements have been fully taken into account in the design, collection and processing of the questionnaire.

Informed Consent Statement: Informed consent was obtained from all subjects involved in the study.

Data Availability Statement: All data sources are fully disclosed in the body of the manuscript.

Acknowledgments: The process of obtaining basic seismic information and historical seismic data was assisted by relevant personnel from Songyuan City Earthquake Administration, Changling County Natural Resources Administration, and Changling County Housing and Urban-Rural Development Administration. The questionnaire distribution process was assisted by relevant personnel from Changling County Education Administration, the principals, class teachers and parents of No. 1 Primary School; No. 2 Primary School; No. 3 Primary School; No. 4 Primary School; No. 1 Junior 
High School; and No. 3 Senior High School in Changling County. We would like to express our deep appreciation for the help provided by the above people.

Conflicts of Interest: The authors declare no conflict of interest.

\section{References}

1. UNDRR. Available online: https://www.undrr.org/terminology/disaster (accessed on 11 November 2021).

2. Li, S.S. Disaster risk communication under disaster prevention and resilient city construction. Beijing Plan. Rev. 2018, 2, 22-26.

3. Li, S.S.; Zhai, G.F.; Zhou, S.T.; Fan, C.J.; Wu, Y.Q.; Ren, C.Q. Insight into the Earthquake Risk Information Seeking Behavior of the Victims: Evidence from Songyuan, China. Int. J. Environ. Res. Publ. Health 2017, 14, 267. [CrossRef] [PubMed]

4. Davis, C.; Keilis-Borok, V.; Molchan, G.; Shebalin, R.; Lahr, R.; Plumb, C. Earthquake prediction and disaster preparedness: Interactive analysis. Nat. Hazards Rev. 2010, 11, 173-184. [CrossRef]

5. Davis, C.; Keilis-Borok, V.; Kossobokov, V.; Soloviev, A. Advance prediction of the March 11, 2011 great east Japan earthquake: A missed opportunity for disaster preparedness. Int. J. Disaster Risk Reduct. 2012, 1, 17-32. [CrossRef]

6. Flint, C.G.; Stevenson, J. Building community disaster preparedness with volunteers: Community emergency response teams in Illinois. Nat. Hazards Rev. 2010, 11, 118-124. [CrossRef]

7. Hoffmann, R.; Muttarak, R. Learn from the past, prepare for the future: Impacts of education and experience on disaster preparedness in the Philippines and Thailand. World Dev. 2017, 96, 32-51. [CrossRef]

8. Sun, Y.Y.; Sun, J.K. Perception, preparedness, and response to tsunami risks in an aging society: Evidence from Japan. Saf. Sci. 2019, 118, 466-474. [CrossRef]

9. Lindell, M.K.; Hwang, S.N. Households' perceived personal risk and responses in a multi-hazard environment. Risk Anal. Int. J. 2008, 28, 539-556. [CrossRef]

10. Xu, D.D.; Liu, E.L.; Wang, X.X.; Tang, H.; Liu, S.Q. Rural households' livelihood capital, risk perception, and willingness to purchase earthquake disaster insurance: Evidence from southwestern China. Int. J. Environ. Res. Publ. Health 2018, 15, 1319. [CrossRef] [PubMed]

11. McCallum, D.B.; Hammond, S.L.; Covello, V.T. Communicating about environmental risks: How the public uses and perceives information sources. Health Educ. Behav. 1991, 18, 349-361. [CrossRef]

12. Wray, R.J.; Kreuter, M.W.; Jacobsen, H.; Clements, B.; Evans, R.G. Theoretical perspectives on public communication preparedness for terrorist attacks. Fam. Community Health 2004, 27, 232. [CrossRef] [PubMed]

13. Palttala, P.; Boano, C.; Lund, R.; Vos, M. Communication Gaps in Disaster Management: Perceptions by Experts from Governmental and Non-Governmental Organizations. J. Cont. Crisis Manag. 2012, 20, 2-12. [CrossRef]

14. Steelman, T.A.; McCaffrey, S.M.; Velez, A.L.K.; Briefel, J.A. What information do people use, trust, and find useful during a disaster? Evidence from five large wildfires. Nat. Hazards 2015, 76, 615-634. [CrossRef]

15. Zhuang, L.M.; He, J.; Yong, Z.L.; Deng, X.; Xu, D.D. Disaster information acquisition by residents of China's earthquake-stricken areas. Int. J. Disaster Risk Reduct. 2020, 51, 1-12. [CrossRef]

16. Alexander, D. World Disasters Report 2005: Focus on information in disasters. Disasters 2006, 30, 377-379. [CrossRef]

17. The General Administration of Quality Supervision, Inspection and Quarantine of the People's Republic of China. GB/T 7027-2002, Basic Principles and Methods for Information Classifying and Coding; China Standards Press: Beijing, China, 2002.

18. Nie, G.Z.; Chen, J.Y.; Li, Z.Q.; Su, G.W.; Gao, J.G.; Liu, H.M. The construction of basic database for earthquake emergency response. Earthquake 2002, 22, 105-112.

19. Su, G.; Nie, G.; Gao, J. The characteristics, classifications and the functions of the information for earthquake emergency response. Earthquake 2003, 23, 27-35.

20. Bai, X.F.; Li, Y.Q.; Chen, J.H.; Dai, Y.Q.; Cao, K.; Cao, Y.B.; Zhao, H.; Gong, Q. Research on earthquake spot emergency response information classification. J. Seismol. Res. 2010, 33, 111-118.

21. Zhu, D.; Xu, J. SMS-based spatio-temporal information collection and management of earthquake disaster. Sci. Surv. Mapp. 2011, 36, 172-174.

22. Dong, M.; Yang, T. Discussion of earthquake emergency disaster information classification. Technol. Earthq. Disaster Prev. 2014, 9 , 937-943.

23. Zhang, Y.; Tang, S.Y.; Wang, Y.; Fan, K.H.; Guo, H.M.; Chen, W.F. Classification and coding of earthquake emergency information products. Technol. Earthq. Disaster Prev. 2016, 11, 132-143.

24. Su, X.; Ma, S.; Qiu, X.; Shi, J.; Zhang, X.; Chen, F. Microblog Topic-Words Detection Model for Earthquake Emergency Responses Based on Information Classification Hierarchy. Int. J. Environ. Res. Public Health 2021, 18, 8000. [CrossRef] [PubMed]

25. Sapountzaki, K. Emergency Evacuation of the Population in Case of Earthquake; Earthquake Planning and Protection Organization (EPPO): Athens, Greece, 2002; Volume 3, p. 72. Available online: https://ecpfe.oasp.gr/sites/default/files/eee_0.pdf (accessed on 1 June 2021).

26. Fokaefs, A.; Sapountzaki, K. Crisis Communication after Earthquakes in Greece and Japan: Effects on Seismic Disaster Management. Sustainability 2021, 13, 9257. [CrossRef]

27. Zhang, Y.; Zhou, Y.; Xu, J.; Yan, J.X.; Tang, S.Y.; Cheng, W.F. Study on the Characteristics of the Earthquake Emergency Information Service Based on User Demands. Technol. Earthq. Disaster Prev. 2021, 16, 211-219.

28. Jeffrey, S.K. Emergency Information Management and Telecommunications. J. Dairy Res. 1997, 46, 1045-1057. 
29. Rego, A.J. National Disaster Management Information Systems \& Networks: An Asian Overview. 2001. Available online: http: / / www.adpc.net/V2007/IKM/ONLINE\%20DOCUMENTS/downloads/PaperAtGdin01.pdf (accessed on 11 November 2021).

30. Yang, K.; Liu, X.C. Information dissemination mechanism of crisis in risk society \& mediated society-Take the 5.12 earthquake as an example. Sci. Econ. Soc. 2009, 27, 120-124.

31. Sha, Y.Z.; Xu, R.X. AT-based Emergency Information Needs Analysis: Framework and Case Study. J. Inf. Resour. Manag. 2011, 2, 32-48.

32. Lei, Z.M.; Wang, Y.Z.; Qiu, J.N.; Wang, X.H. Multi-dimensional Analysis of Emergency Information Needs. Inf. Sci. 2014, 12, 133-137.

33. Wang, H.Y.; Li, Z.X.; Zhang, T.; Feng, J.; Zhang, X.Y. Information requirement of earthquake emergency response and suggestions. J. Catastrophol. 2016, 31, 176-180.

34. Zhou, Y.; Zhang, Y.; Wang, Y.; Xu, J.; Chen, W.F. Analysis of earthquake emergency information product service needs: Taking Sichuan Qingbaijiang Ms5.1 Earthquake for example. Earthq. Res. Sichuan 2021, 1, 30-32, 38.

35. Zhang, Y.S.; Cao, Y.B.; Wang, X.; Deng, S.R.; Du, H.G.; Zhang, F.H. Analysis of the Demand for Products of the Earthquake Emergency Information: A Case Study of the Members of the Earthquake Relief Headquarters in Yunnan. Technol. Earthq. Disaster Prev. 2021, 16, 193-201.

36. Sayers, E.L.P.; Parker, A.M.; Seelam, R.; Finucane, M.L. How disasters drive media channel preferences: Tracing news consumption before, during, and after Hurricane Harvey. J. Cont. Crisis Manag. 2021, 29, 342-356. [CrossRef]

37. Finazzi, F. Fulfilling the information need after an earthquake: Statistical modelling of citizen science seismic reports for predicting earthquake parameters in near realtime. J. R. Statist. Soc. A 2020, 183, 857-882. [CrossRef]

38. Becker, S.M. Emergency communication and information issues in terrorist events involving radioactive materials. Biosecurity Bioterror. 2004, 2, 195-207. [CrossRef] [PubMed]

39. Burger, B.; Gochfeld, M.; Jeitner, C. Trusted information sources used during and after Superstorm Sandy: TV and radio were used more often than Social Media. J. Toxicol. Environ. Health Part A 2013, 76, 1138-1150. [CrossRef]

40. Lindell, M.K.; Lu, J.C.; Prater, C.S. Household decision making and evacuation in response to Hurricane Lili. Nat. Hazards Rev. 2005, 6, 171-179. [CrossRef]

41. Cretikos, M.; Eastwood, K.; Dalton, C.; Merritt, T.; Tuyl, F.; Winn, L.; Durrheim, D. Household disaster preparedness and information sources: Rapid cluster survey after a storm in New South Wales, Australia. BMC Public Health 2008, 8, 1-9. [CrossRef] [PubMed]

42. Heath, R.L.; Lee, J.; Ni, L. Crisis and Risk Approaches to Emergency Management Planning and Communication: The Role of Similarity and Sensitivity. J. Public Relat. Res. 2008, 21, 123-141. [CrossRef]

43. Holmes, B.J.; Henrich, N.; Hancock, S.; Lestou, V. Communicating with the public during health crises: Experts' experiences and opinions. J. Risk Res. 2009, 12, 793-807. [CrossRef]

44. Perez-Lugo, M. Media Uses in Disaster Situations: A New Focus on the Impact Phase. Sociol. Inq. 2004, 74, 210-225. [CrossRef]

45. Taylor, J.G.; Gillette, S.C.; Hodgson, R.W.; Downing, J.L.; Hogan, J.T. Informing the network: Improving communication with interface communities during wild land fire. Hum. Ecol. Rev. 2007, 14, 198-211.

46. Kuller, M.; Schoenholzer, K.; Lienert, J. Creating effective flood warnings: A framework from a critical review. J. Hydrol. 2021, 602, 126708. [CrossRef]

47. Heath, R.L.; O'Hair, H.D. (Eds.) Handbook of Risk and Crisis Communication; Routledge: London, UK, 2009.

48. Petrun Sayers, E.L.; Parker, A.M.; Ramchand, R.; Finucane, M.L.; Parks, V.; Seelam, R. Reaching vulnerable populations in the disaster-prone US Gulf Coast: Communicating across the crisis lifecycle. J. Emerg. Manag. 2019, 17, 271-286. [CrossRef]

49. Pollard, W.E. Public perceptions of information sources concerning bioterrorism before and after anthrax attacks: An analysis of national survey data. J. Health Commun. 2003, 8 (Suppl. S1), 93-103. [CrossRef]

50. Freberg, K. Intention to comply with crisis messages communicated via social media. Public Relat. Rev. 2012, 38, 416-421. [CrossRef]

51. Arora, S. Post-disaster communities on social media: Citizen participation in crisis communication after the Nepal earthquake. $J$ Appl. Commun. Res. 2015. [CrossRef]

52. Bikar, S.S.; Rathakrishnan, B.; Kamaluddin, M.R.; Che Mohd Nasir, N.; Mohd Nasir, M.A. Social Sustainability of Post-Disaster: How Teachers Enable Primary School Students to Be Resilient in Times of Ranau Earthquake. Sustainability 2021, $13,7308$. [CrossRef]

53. Liu, B.F.; Fraustini, J.D.; Jin, Y. Social Media Use during Disaster: How Information Form and Source Influence Intended Behavioral Responses. Commun. Res. 2016, 43, 626-646. [CrossRef]

54. Amiresmaili, M.; Zolala, F.; Nekoei-Moghadam, M.; Salavatian, S.; Chashmyazdan, M.; Soltani, A.; Savabi, J. Role of Social Media in Earthquake: A Systematic Review. Iran. Red. Crescent Med. J. 2021, 23, e447.

55. Malasig, B.J.; Quinto, E.J. Functions of and communication behavior on twitter after the 2015 Nepal earthquake. Malays. J. Communic. 2016, 32, 140-157. [CrossRef]

56. Gray, B.; Weal, M.J.; Martin, D. Social media during multi-hazard disasters: Lessons from the Kaikoura Earthquake. Int. J. Saf. Secur. Eng. 2017, 7, 313-323.

57. Taylor, K.; Priest, S.; Sisco, H.F.; Banning, S.; Campbell, K. Reading Hurricane Katrina: Information Sources and Decision-making in Response to a Natural Disaster. Soc. Epistemol. 2009, 23, 361-380. [CrossRef] 
58. Communicating with Communities. Nepal Earthquake Response. Online Report. Available online: https:/ /www.internews.org/ sites/default/files/resources/NepalAssessment_CwC_Chautara_May2015.pdf (accessed on 24 February 2021).

59. Perera, D.; Seidou, O.; Agnihotri, J.; Rasmy, M.; Smakhtin, V.; Coulibaly, P.; Mehmood, H. Flood Early Warning Systems: A Review of Benefits, Challenges and Prospects. Challenges and Prospects; United Nations University Institute for Water, Environment and Health: Hamilton, ON, Canada, 2019.

60. Bean, H.; Sutton, J.; Liu, B.F.; Madden, S.; Wood, M.M.; Mileti, D.S. The study of mobile public warning messages: A research review and agenda. Rev. Commun. 2015, 15, 60-80. [CrossRef]

61. Potter, S.H.; Kreft, P.V.; Milojev, P.; Noble, C.; Montz, B.; Dhellemmes, A.; Woods, R.J.; Gauden-Ing, S. The influence of impactbased severe weather warnings on risk perceptions and intended protective actions. Int. J. Disaster Risk Reduct. 2018, $30,34-43$. [CrossRef]

62. Weyrich, P.; Scolobig, A.; Bresch, D.N.; Patt, A. Effects of impact-based warnings and behavioral recommendations for extreme weather events. Weather Clim. Soc. 2018, 10, 781-796. [CrossRef]

63. Fink, S. Crisis Management: Planning for the Inevitable; American Management Association: New York, NY, USA, 1986.

64. Chen, C.K.; Li, Z.; Sun, Y.F. Study on Characteristics of Disaster Information Transmission Based on Complex Networks. J. Catastrophol. 2008, 23, 126-129.

65. Tan, K.Z. Public Relations (Theory E Case), 2nd ed.; Tsinghua University Press: Beijing, China, 2015.

66. Yang, K.; Liu, X.C. Government, Media and Public: Research on Emergency Mechanism of Emergency Information Dissemination; China Social Sciences Press: Beijing, China, 2010.

67. Xu, L. The Construction of Modern Public Cultural Service System in the Perspective of Communication Studies; World Culture Books: Hong Kong, China, 2015; p. 87.

68. Zhou, Y.S. Research on Response to Major Public Crisis; People's Publishing House: Beijing, China, 2013 ; p. 190.

69. Dai, F.X. Preventive Ideas and Measures against Possible Troubles; Social Sciences Academic Press (CHINA): Beijing, China, 2013.

70. He, S.K.; Tang, Q. Study on classification of cities in the aspect of earthquake prevention and disaster mitigation. J. Catastrophol. 1994, 9, 62-66.

71. Yu, X.H. Structural Activity Analysis of Faults in the Southeast of Songliao Basin. Ph.D. Thesis, Institute of Geology China Earthquake Administration, Beijing, China, 2019.

72. Li, C.Y.; Wang, Y.P.; Zhang, L.H.; Li, Z.T.; Li, C.F. Causative Tectonic Conditions of the Historic Earthquake $(\mathrm{M}=63 / 4)$ in 1119 in Songyuan Area. Earthq. Res. China 1999, 15, 237-246.

73. Liu, S.; Wu, P.; Yang, J.S.; Su, J.R. Preliminary study of seismic anisotropy in Qianguo area, Jilin Province. Chin. J. Geophys. 2014, 57, 2088-2098.

74. Yu, G.C.; Yao, Y.S.; Zhang, L.F.; Wang, Q.L.; Wu, H.B. Study on Genesis of Ms. $\geq 5$ Songyuan Earthquake Swarm in Jilin Province in 2013. J. Geod. Geodyn. 2020, 40, 534-539.

75. Songyuan City in Jilin Province Occurred Twice Earthquakes in Ten Minutes, and at Least Thirteen Persons Injured with Two Severely Injured. Available online: http:/ / news.163.com/13/1101/06/9CITU0IJ00014Q4Phtml (accessed on 18 January 2017).

76. Songyuan Earthquake in Jilin Province Affected Almost 60,000 Homes, and the Economic Loss Is Up to CNY 20 Billion. Available online: http:/ / society.people.com.cn/n/2013/1123/c1008-23635080.html (accessed on 18 January 2017).

77. Zhai, G.F.; Suzuki, T. Public willingness to pay for environmental management, risk reduction and economic development: Evidence from Tianjin, China. China Econ. Rev. 2008, 19, 551-566. [CrossRef]

78. Zhang, W.T. Basic SPSS Statistical Analysis Tutorial, 3rd ed.; Higher Education Press: Beijing, China, 2017 ; p. 138.

79. Finazzi, F. The earthquake network project: Toward a crowdsourced smartphone-based earthquake earlywarning system. Bull. Seism. Soc. Am. 2016, 106, 1088-1099. [CrossRef]

80. Basu, M.; Ghosh, S.; Jana, A.; Bandyopadhyay, S.; Singh, R. Resource mapping during a natural disaster: A case study on the 2015 Nepal earthquake. Int. J. Disas. Risk Reduct. 2017, 24, 24-31. [CrossRef]

81. Basu, M.; Ghosh, S.; Jana, A.; Bandyopadhyay, S.; Singh, R. Medical requirements during a natural disaster: A case study on WhatsApp chats among medical personnel during the 2015 Nepal earthquake. Disas. Med. Public Health Prep. 2017, 11, 652-655. [CrossRef]

82. Ye, P.; Zhang, X.; Huai, A.; Tang, W. Information Detection for the Process of Typhoon Events in Microblog Text: A Spatio-Temporal Perspective. ISPRS Int. J. Geo-Inf. 2021, 10, 174. [CrossRef]

83. Yates, D.; Paquette, S. Emergency knowledge management and Social Media technologies: A case study of the 2010 Haitian earthquake. Int. J. Inf. Manag. 2011, 31, 6-13. [CrossRef]

84. Dong, R.; Li, L.; Zhang, Q.; Cai, G. Information diffusion on social media during natural disasters. IEEE Trans. Comput. Soc. Systems. 2018, 5, 265-276. [CrossRef] [PubMed]

85. Su, X.; Zhang, X.; Hu, C.; Zou, Z.; Qiu, X. Research on the extraction of earthquake's hot topic-words from microblog based on improved TF-PDF algorithm. Geogr. Geo-Inf. Sci. 2018, 34, 90-95.

86. Thapa, L. Spatial-temporal analysis of social media data related to Nepal Earthquake 2015. ISPRS Int. Arch. Photogramm. Remote Sens. Spat. Inf. Sci. 2016, XLI-B2, 567-571. [CrossRef]

87. Qi, M.; Qi, W.H.; Su, G.W. 2017 Sichuan Jiuzhaigou M7.0 Earthquake Sentiment Analysis Based on Sina Weibo. North China Earthq. Sci. 2020, 38, 57-63. 
88. Gulesan, O.B.; Anil, E.B.; Boluk, P.C. Social media-based emergency management to detect earthquakes and organize civilian volunteers. Int. J. Disaster Risk Reduct. 2021, 65, 102543. [CrossRef]

89. Li, L.Y.; Bensi, M.; Cui, Q.B.; Baecher, G.B.; Huang, Y. Social media crowdsourcing for rapid damage assessment following a sudden-onset natural hazard event. Int. J. Inf. Manag. 2021, 60, 102378. [CrossRef]

90. Li, L.F.; Zhang, Q.P.; Tian, J.; Wang, H.L. Characterizing information propagation patterns in emergencies: A case study with Yiliang Earthquake. Int. J. Inf. Manag. 2018, 38, 34-41. [CrossRef]

91. Maceda, L.L.; Llovido, J.L.; Palaoag, T.D. Corpus analysis of earthquake related tweets through topic modelling. Int. J. Mach. Learn Comput. 2017, 7, 194-197. [CrossRef]

92. Tan, Y.J.; Maharajah, R. What Googling Trends Tell Us about Public Interest in Earthquakes. Seismol. Res. Let. 2018, 89, 653-657. [CrossRef]

93. Gizzi, F.T.; Kam, J.; Porrini, D. Time windows of opportunities to fight earthquake under-insurance: Evidence from Google Trends. Humanit. Soc. Sci. Commun. 2020, 7, 61. [CrossRef]

94. Wang, L.; Jia, J.M. Risk perception dynamics in unexpected disaster events: Evidence from online search. Manag. Rev. 2014, 5, 169-176.

95. Li, S.S.; Zhai, G.F.; Fan, C.J.; Chen, J.; Li, L. The Need for Cognition on Earthquake Risk in China Based on Psychological Distance Theory. Complexity 2020, 2020, 8882813. [CrossRef] 